\title{
Structural Diversity in Tetrakis(4-pyridyl)porphyrin Supramolecular Building Blocks
}

Manish Kumar Mishra, ${ }^{a+}$ Hemant Choudhary ${ }^{a,}$ David B. Cordes,${ }^{a, t}$ Steven P. Kelley,,$* *$ Robin D. $\operatorname{Rogers}^{a, *}$

College of Arts \& Sciences, The University of Alabama, Tuscaloosa, AL 35487, USA

Department of Chemistry, University of Missouri, Columbia, MO 65211, USA

525 Solutions, Inc., P.O. Box 2206, Tuscaloosa, AL 35403, USA

KEYWORDS: Porphyrins, coordination polymers, topological analysis, liquid-liquid diffusion, hydrogen bonding

In memory of a pioneer in crystal engineering, Prof. Israel Goldberg, we report a series of new framework solids, based on the ligand tetrakis(4-pyridyl)porphyrin (TPyP). Spontaneous reactions of TPyP with seven different metal salts under liquid-liquid diffusion at ambient temperature show that the formation of ionic compounds is preferred to coordination polymers due to increased conformational freedom. Two coordination networks, $\left\{\left(\mathrm{HgI}_{2}\right)_{2}(\mathrm{TPyP})\right\}_{n} \cdot 4 n \mathrm{CHCl}_{3} \cdot 2 n \mathrm{TCE}(\mathrm{TCE}=$ 1,1,2,2-tetrachloroethane), and $\left\{\left(\mathrm{Ba}(\mu 1,1-\mathrm{NCS})(\mu 1,1,3-\mathrm{NCS})\left(\mathrm{H}_{2} \mathrm{O}\right)(\mathrm{MeCN})\right)_{2}(\mathrm{TPyP})\right\}_{n} \cdot 4 n \mathrm{H}_{2} \mathrm{O}$, displayed a new isomeric form of the known $\left[\left(\mathrm{HgI}_{2}\right)_{2}(\mathrm{TPyP})\right]_{\star}$ polymeric motif, and a two- 
dimensional honeycomb polymeric motif linked by hydrogen-bonding into a three dimensional moganite $(\mathrm{mog})$ net, respectively. Four protonated porphyrinic salts, $\left[\mathrm{H}_{3} \mathrm{TPyP}_{[}\left[\mathrm{PF}_{6}\right]_{3} \cdot 0.5 \mathrm{TCE}\right.$, $\left[\mathrm{H}_{2} \mathrm{TPyP}\right]\left[\mathrm{I}_{3}\right]_{2} \cdot 2 \mathrm{MeOH},\left[\mathrm{H}_{4} \mathrm{TPyP}\right]\left[\mathrm{UO}_{2} \mathrm{Cl}_{4}\right]_{2} \cdot 6 \mathrm{MeCN}$, and $\left[\mathrm{H}_{4} \mathrm{TPyP}\right]\left[\mathrm{Th}\left(\mathrm{NO}_{3}\right)_{6}\right]\left[\mathrm{NO}_{3}\right]_{2}$, were observed which hydrogen bond to give one- or two-dimensional networks, or in the case of $\left[\mathrm{H}_{4} \mathrm{TPyP}\right]\left[\mathrm{UO}_{2} \mathrm{Cl}_{4}\right]_{2} \cdot 6 \mathrm{MeCN}$, a discrete dinuclear hydrogen-bonded complex. In one case, a neutral, hydrogen-bonded complex, $\mathrm{Ce}\left(\mathrm{NO}_{3}\right)_{3}(\mathrm{MeOH})_{3}\left(\mathrm{H}_{2} \mathrm{O}\right) \cdot \mathrm{TPyP} \cdot \mathrm{TCE} \cdot \mathrm{H}_{2} \mathrm{O}$, was formed which adopts a three-dimensional, self-penetrated variant of the face-centered cubic (fcc) network. These new structures represent hybrid organic-inorganic crystalline compounds in which the multidentate porphyrin units, having both hydrogen bonding, as well as coordination functionalities, are interlinked through the inorganic connectors into self-assembled three-dimensional architectures. This work shows the relative stability of noncovalently bound $v s$. coordination networks as well as the effective potential of the TPyP building block to construct supramolecular assemblies in the presence or absence of coordinating ions as linkers.

\section{Introduction}

Porphyrin derivatives are among the key synthetic building blocks in supramolecular chemistry. Shortly after Desiraju's publication of the supramolecular synthon concept,' a report by Kumar, Balasubramanian, and Goldberg described one of the first strategic applications of this concept, exploiting the rigidity and directionality of tetraphenylporphyrins with electron withdrawing groups at the para positions. ${ }^{2}$ Our group showed that the related tetrakis(4-pyridyl)porphyrin (TPyP) could be used to assemble supramolecular structures via the pyridyl nitrogen atoms with optical properties that could be tuned by independent metallation of the porphyrin core. ${ }^{3}$ 
Tetraphenylporphyrin derivatives and analogs continue to be used this way, for instance as spacers in metal organic frameworks which take advantage of the catalytic activity ${ }^{45}$ and optical properties ${ }^{6}$ of metallated porphyrins.

Our group has continued research on the supramolecular chemistry of TPyP due to the flexibility of having up to four independently functionalizable, directional handles. A TPyP molecule functionalized with or coordinated to an arbitrary group at one pyridine position has at least 38 potential derivatives considering only whether the other rings are free base, alkylated, protonated, or coordinating, and whether the core is metallated or not. Because TPyP can act as a ligand itself, even individual TPyP derivatives have been observed to have multiple polymeric structures, a phenomenon termed supramolecular isomerism.? Interestingly, despite this very wide design space, TPyP appears rather under-explored compared to other tetraphenylporphyrin derivatives; the Cambridge Structural Database contains 235 entries with a tetrakis(4pyridyl)porphyrin core compared to 3695 entries for any tetraphenylporphyrin derivative (with or without a heteroatom at the 4-position). ${ }^{s}$

There are a number of common structural and topological features that have been observed in architectures containing TPyP which are dictated by its rigidity and self complementarity. These features include a variety of one-dimensional chains ${ }^{3923}$ two-dimensional nets based on the $(4,4)$ topology ${ }^{102022450}$ which can be cross-linked into three dimensional networks, ${ }^{\text {s.1.3 }}$ and three-

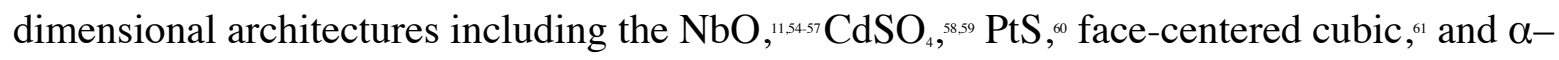
polonium nets. ${ }^{61}$ Further, the architectures that have been encountered include a large number of potentially porous networks, often containing disordered solvent molecules. ${ }^{2606}$ The range of architectures expands when TPyP is combined with noncovalently bound coformers. Zero dimensional systems can be attained when TPyP acts as a guest in host-guest complexes ${ }^{1076}$ or is 
completely surrounded by counterions. ${ }^{7-79}$ Access to permanent cations through alkylation has led to supramolecular systems held together through ionic interactions, including infinite ionic stacks with counterions (often other porphyrin derivatives) s.8.8 $^{80}$ and the formation of polar and nonpolar segregated zones in dodecylated TPyP cations synthesized by our group as potential ionic liquid dyes. ${ }^{84}$ In metallated porphyrins the axial ligands can be used to introduce supramolecular functionality such as hydrogen bond ${ }^{85}$ and halogen bond donors ${ }^{8687}$

Crystal engineering with TPyP and metal ions is particularly likely to lead to unanticipated structures. This is because metal ions may attack the coordinating sites in a number of ways and, in protic solvents, may promote the protonation of TPyP and form complex counterions. Herein we present the synthesis and structural characterization of a series of new TPyP-containing compounds which explore this structural variability. These include two coordination polymers, $\left\{\left(\mathrm{HgI}_{2}\right)_{2}(\mathrm{TPyP})\right\}_{n} \cdot 4 n \mathrm{CHCl}_{3} \cdot 2 n \mathrm{TCE}(\mathbf{1}, \mathrm{TCE}=1,1,2,2-$ tetrachloroethane $)$, and $\{[\mathrm{Ba}(\mu-1,1-$ $\left.\left.\mathrm{NCS})(\mu-1,1,3-\mathrm{NCS})\left(\mathrm{H}_{2} \mathrm{O}\right)(\mathrm{MeCN})\right)_{2}(\mathrm{TPyP})\right\}_{n} \cdot 4 n \mathrm{H}_{2} \mathrm{O}(2)$; four protonated porphyrinic salts, $\left[\mathrm{H}_{3} \mathrm{TPyP}\right]\left[\mathrm{PF}_{6}\right]_{3} \cdot 0.5 \mathrm{TCE}(\mathbf{3}),\left[\mathrm{H}_{2} \mathrm{TPyP}\right]\left[\mathrm{I}_{3}\right]_{2} \cdot 2 \mathrm{MeOH}(\mathbf{4}),\left[\mathrm{H}_{4} \mathrm{TPyP}\right]\left[\mathrm{UO}_{2} \mathrm{Cl}_{4}\right]_{2} \cdot 6 \mathrm{MeCN}(\mathbf{5})$, and $\left[\mathrm{H}_{4} \mathrm{TPyP}\right]\left[\mathrm{Th}\left(\mathrm{NO}_{3}\right)_{6}\right]\left[\mathrm{NO}_{3}\right]_{2}(\mathbf{6})$; and a neutral hydrogen-bonded complex, $\mathrm{Ce}\left(\mathrm{NO}_{3}\right)_{3}(\mathrm{MeOH})_{3}\left(\mathrm{H}_{2} \mathrm{O}\right) \cdot \mathrm{TPyP} \cdot \mathrm{TCE} \cdot \mathrm{H}_{2} \mathrm{O}(7)$. These seven complexes show a wide range of topological and structural features, several of which have not been seen previously in compounds involving TPyP.

\section{Experimental}

2.1 Materials and methods. All chemicals were purchased from Aldrich (Milwaukee, WI), except for $\mathrm{UO}_{2} \mathrm{Cl}_{2}$ which was purchased from Isotope Products Laboratories (Valencia, CA). 
The single crystals of 1-7 were grown using layering techniques at ambient temperatures as follows. 1: TPyP (31 mg, $50 \mu \mathrm{mol})$ dissolved in TCE-CHCl $-\mathrm{MeOH}(2: 2: 1,20 \mathrm{~mL})$ was layered with a methanolic solution of $\mathrm{HgI}_{2}(46 \mathrm{mg}, 0.1 \mathrm{mmol}, 10 \mathrm{~mL})$ to form $\left\{\left(\mathrm{HgI}_{2}\right)_{2}(\mathrm{TPyP})\right\}_{n} \cdot 4 n \mathrm{CHCl}_{3} \cdot 2 n$ TCE. 2: TPyP $(31 \mathrm{mg}, 50 \mu \mathrm{mol})$ dissolved in TCE-MeOH $(3: 1,20$ $\mathrm{mL})$ was layered with a $\mathrm{MeCN}$ solution of $\mathrm{Ba}(\mathrm{SCN})_{2} \cdot 3 \mathrm{H}_{2} \mathrm{O}(31 \mathrm{mg}, 0.1 \mathrm{mmol}, 10 \mathrm{~mL})$ to form $\left\{\left(\mathrm{Ba}(\mu 1,1-\mathrm{NCS})(\mu 1,1,3-\mathrm{NCS})\left(\mathrm{H}_{2} \mathrm{O}\right)(\mathrm{MeCN})\right)_{2}(\mathrm{TPyP})\right\}_{n} \cdot 4 n \mathrm{H}_{2} \mathrm{O} .3:$ TPyP $(31 \mathrm{mg}, 50 \mu \mathrm{mol})$ dissolved in TCE-MeOH (3:1, $20 \mathrm{~mL})$ was layered with a methanolic solution of $\mathrm{AgPF}_{6}(25 \mathrm{mg}$, $0.1 \mathrm{mmol}, 10 \mathrm{~mL})$ to form $\left[\mathrm{H}_{3} \mathrm{TPyP}\right]\left[\mathrm{PF}_{6}\right]_{3} \cdot 0.5 \mathrm{TCE} .4$ : TPyP $(31 \mathrm{mg}, 50 \mu \mathrm{mol})$ dissolved in TCE$\mathrm{MeOH}(3: 1,20 \mathrm{~mL})$ was layered with a methanolic solution of $\mathrm{CrI}_{3}(43 \mathrm{mg}, 0.1 \mathrm{mmol}, 10 \mathrm{~mL})$ to form $\left[\mathrm{H}_{4} \mathrm{TPyP}\right]\left[\mathrm{I}_{3}\right]_{4} \cdot 2 \mathrm{MeOH} .5$ : TPyP $(31 \mathrm{mg}, 50 \mu \mathrm{mol})$ dissolved in TCE-MeOH $(3: 1,20 \mathrm{~mL})$ was layered with a MeCN solution of $\mathrm{UO}_{2} \mathrm{Cl}_{2}(34 \mathrm{mg}, 0.1 \mathrm{mmol}, 10 \mathrm{~mL})$ to form $\left[\mathrm{H}_{4} \mathrm{TPyP}\right]\left[\mathrm{UO}_{2} \mathrm{Cl}_{4}\right]_{2} \cdot 6 \mathrm{MeCN}$. 6: TPyP $(31 \mathrm{mg}, 50 \mu \mathrm{mol})$ dissolved in TCE-MeOH $(3: 1,20 \mathrm{~mL})$ was layered with a methanolic solution of $\mathrm{Th}\left(\mathrm{NO}_{3}\right)_{4} \cdot 5 \mathrm{H}_{2} \mathrm{O}(57 \mathrm{mg}, 0.1 \mathrm{mmol}, 10 \mathrm{~mL})$ to form $\left[\mathrm{H}_{4} \mathrm{TPyP}\right]\left[\mathrm{Th}\left(\mathrm{NO}_{3}\right)_{6}\right]\left[\mathrm{NO}_{3}\right]_{2} .7:$ TPyP $(31 \mathrm{mg}, 50 \mu \mathrm{mol})$ dissolved in TCE-MeOH $(3: 1,20 \mathrm{~mL})$ was layered with a methanolic solution of $\mathrm{Ce}\left(\mathrm{NO}_{3}\right)_{3} \cdot 6 \mathrm{H}_{2} \mathrm{O}(43 \mathrm{mg}, 0.1 \mathrm{mmol}, 10 \mathrm{~mL})$ to form $\mathrm{Ce}\left(\mathrm{NO}_{3}\right)_{3}(\mathrm{MeOH})_{3}\left(\mathrm{H}_{2} \mathrm{O}\right) \cdot \mathrm{TPyP} \cdot \mathrm{TCE} \cdot \mathrm{H}_{2} \mathrm{O}$.

$2.2 X$-ray crystallography. Single crystal X-ray diffraction (SCXRD) data for single crystal structural determinations of complexes 1-7 were collected on a Bruker SMART CCD area detector-equipped diffractometer (Bruker AXS, Madison, WI) with graphite monochromated Mo-K $\alpha$ radiation $\left(\lambda=0.71073 \AA\right.$ Á). The crystals were cooled to $-100^{\circ} \mathrm{C}$ under a cold stream of nitrogen using an LT-2 cryostat (Bruker AXS). Intensities were corrected for Lorentz and polarization effects ${ }^{88}$ and a multi-scan absorption correction ${ }^{89}$ was applied. The structures were solved by direct methods and refined on $F^{2}$ using all data by full-matrix least-squares procedures 
using SHELXL v.2017..$^{\circ}$ Non-hydrogen atoms corresponding to ordered parts of the structure were readily located and refined anisotropically. Hydrogen atoms bonded to carbon were placed in calculated positions, and the coordinates were constrained to ride on the carrier atoms. Methyl group hydrogen atoms were refined using a riding-rotating model. Hydrogen atoms bonded to nitrogen were located from the difference Fourier maps in all cases, except for those in $\mathbf{3}$ and $\mathbf{7}$ where hydrogen atoms on protonated nitrogen atoms were placed in calculated positions and constrained to ride on the nitrogen atoms. Hydrogen atoms bonded to oxygen were located from the difference Fourier maps in all cases, except for those in $\mathbf{7}$ and those on lattice water molecules in $\mathbf{2}$ which were omitted from the refinement but included in the formula. All hydrogen atom thermal parameters were constrained to ride on the carrier atoms. Topological analysis of the complexes was carried out using OLEX." Ellipsoid plots were generated using Olex2 v.1-2,2: and packing plots were made using Mercury 4.1.0 (Cambridge Crystallographic Data Center, Cambridge, UK).9.

In both $\mathbf{1}$ and $\mathbf{3}$, highly disordered solvent molecules were found to be present which could not be satisfactorily modeled. These were removed from the atom list for refinement, and the SQUEEZE routine in PLATON" was applied in each case. The contribution to the diffraction pattern of diffuse solvent and anion fragments was removed, and modified $F_{\circ}{ }^{2}$ values were written to a new HKL file. The number of electrons per unit cell thus located was included in the formula, formula weight, calculated density, $\mu$ and $F(000)$, and was determined to be either two molecules of TCE per TPyP for 1, or half a molecule of TCE per TPyP for 3. (Note: Due to the use of an older version of SQUEEZE, false CheckCIF alerts are generated for the presence of solvent accessible voids and mismatches between calculated and reported formulae, $\mu$, and $F(000)$ which would ordinarily be suppressed.) 
The structure of 7 was found to be affected by twinning, with a twin law of -1 $0000-10101$. The Flack parameter ${ }^{9596}$ of the structure indicated that racemic twinning was occurring as well, so this was incorporated into the twin refinement. Possibly as a result of the twinning occurring in the crystal, the positions of the methanolic hydrogen atoms and those of both the coordinated and non-coordinated water molecules could not be determined from the difference Fourier map. A rigid group restraint was also applied to all thermal ellipsoids in $\mathbf{7}$ in order to compensate for the loss of data-to-parameters caused by twinning and other systematic errors. ${ }^{97}$

Structure 1 has significant residual electron density peaks outside the $\mathrm{Hg}$ and I atom locations which may be caused by packing defects which result in these heavy atom sites occupying nearby locations and does not impact the interpretation of the structure, which is supported by the very characteristic coordination mode of $\mathrm{Hg}(\mathrm{II})$. Due to a software error, the estimated minimum and maximum X-ray transmission factors of $\mathbf{2}$ were not logged; these were applied using the same semi-empirical multi-scan method as the other structures with spherical harmonic equation orders of 5 and 8 and an estimated $\mu \cdot \mathrm{r}$ of equivalent sphere of 0.2 . For structure 5 a hardware error on the final scan caused a fraction data to be unusable, resulting in low completeness, but not otherwise having serious effects on the refinement. In structures $\mathbf{5}$ and $\mathbf{6}$ the bond lengths for several N-H bonds refined to unrealistically long values, this is most likely due to the dominating effects of the heavy atom in the structure. The free refinements of $\mathrm{H}$ atom positions in these structures were retained because the experimental confirmation of unrestrained $\mathrm{H}$ atom locations is of greater value to the study than the actual $\mathrm{N}-\mathrm{H}$ bond distance.

\section{Results and Discussion}


3.1 Crystallization and role of metal ions: Direct addition of the metal salts to solutions of TPyP led to immediate precipitation of powders, as did direct mixing of solutions of the metal salts and solutions of TPyP. Single crystals large enough for study by SCXRD methods could only be obtained by layering of a solution of the metal salt in a polar solvent, $\mathrm{MeCN}$ or $\mathrm{MeOH}$, on top of a solution of TPyP in mixed TCE-MeOH or TCE-CHCl ${ }_{3}-\mathrm{MeOH}$, allowing slow diffusion at room temperature. The metal-containing solutions are sources of both inorganic ions and protons from adventitious water or hydrated starting materials. These ions likely diffuse into the TPyP layer much faster than TPyP diffuses into the inorganic layer, given the much larger size and low solubility of TPyP. The crystallizations can thus be expected to take place mainly in the TPyP layer with inorganic ions as the limiting reactant. There are potentially many combinations of TPyP with the multiple inorganic ions entering the solution in each system, and the crystallizations indicate which of these combinations produces the most stable and least soluble crystal structure.

All reactions are summarized in Scheme 1. The structures of $\mathbf{1}$ and $\mathbf{2}$ were determined to be coordination polymers, those of $3-\mathbf{6}$ were found to be porphyrinic salts, and 7 to be a hydrogenbonded complex. The results indicate that, in general, salts are more stable than coordination polymers directly linked by metal ions. The reason for this appears to be that, while the salts lack any interactions that are individually as strong as the metal-pyridine dative interaction would be, the protonated TPyP cation is far more flexible as a structural building block. $\mathrm{H}^{+}$does not have a coordination sphere that needs to be filled, and thus the TPyP moiety can have any of a wide range of orientations with respect to the counterion. The counterion does not have to be strongly interacting, but it does have to fill space. While $\left[\mathrm{PF}_{6}\right]$ and $\left[\mathrm{I}_{3}\right]$ are able to dissociate from the metal-containing starting material and form metal-free salts, $\mathrm{Cl}$ and $\left[\mathrm{NO}_{3}\right]$ do not, remaining 
associated with the metal ions to form polyatomic anions even though the latter two anions are more basic. Compounds $\mathbf{1}$ and $\mathbf{2}$, incidentally, likely form coordination polymers because the metal starting materials, $\mathrm{HgI}_{2}$ and $\mathrm{Ba}(\mathrm{SCN})_{2}$, do not form stable anionic complexes in solvents like $\mathrm{MeOH}$ or $\mathrm{MeCN}$, and their counterions are too small to stabilize an ionic lattice with TPyP counterions. Compound 7 is the exception to the above, forming neither a salt nor a coordination polymer, and in this unusual case the two neutral moieties happen to form a net that is capable of interpenetration, as discussed further. 


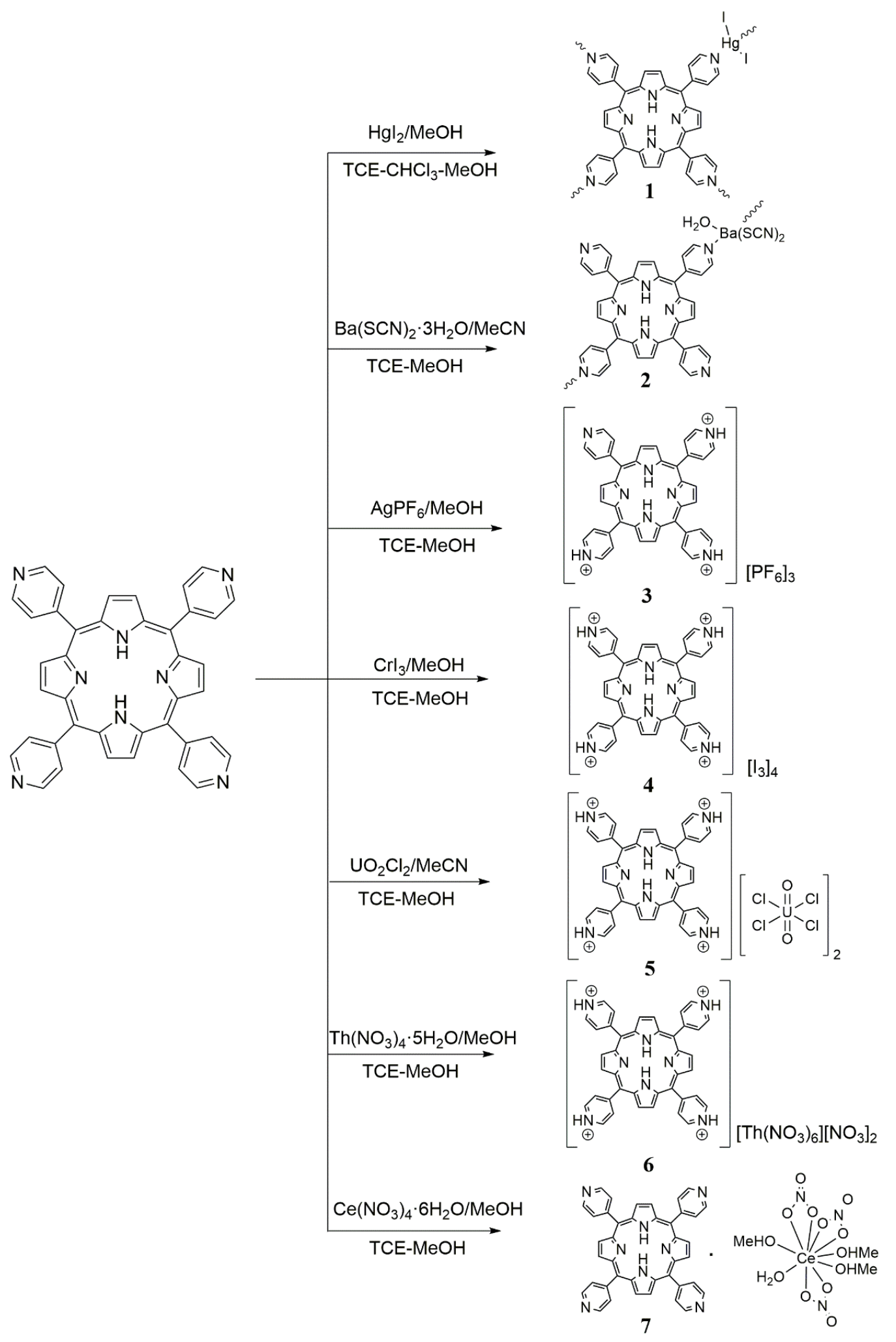

Scheme 1: Crystallizations of 1-7 (solvents of crystallization omitted from product formulas). 
Regardless of whether TPyP is bridged directly through metal coordination or linked through a more complicated network of noncovalent interactions, its size and rigidity give it a decisive influence on the overall structure. The supramolecular features of the individual structures will be discussed in detail.

\subsection{Structure Descriptions and Topography}

Structure of $\left\{\left(\mathrm{HgI}_{2}\right)_{2}(\mathrm{TPyP})\right\}_{n} \cdot \mathbf{4 n} \mathrm{CHCl}_{3} \cdot \mathbf{2 n T C E}(1)$. Compound 1 , formed from the reaction of TPyP and $\mathrm{HgCl}_{2}$, crystallizes in the orthorhombic space group Pnnm. The asymmetric unit consists of half a four-coordinate $\mathrm{Hg}(\mathrm{II})$ cation, two half I- anions, a quarter of a TPyP ligand, a $\mathrm{CHCl}_{3}$ solvent molecule, and further disordered solvent (determined to consist of two molecules of TCE per TPyP using the SQUEEZE routine in PLATON). The centroid of the porphyrin ring lies on a two-fold rotation axis and a perpendicular mirror plane to give a porphyrin with four symmetry equivalent pyridine groups (Figure 1a). The complex comprises tetrahedrally coordinated $\mathrm{Hg}(\mathrm{II})$ cations linking TPyP molecules to form one-dimensional metallamacrocyclic coordination polymers propagating along the crystallographic $c$-axis (Figure 1b). 


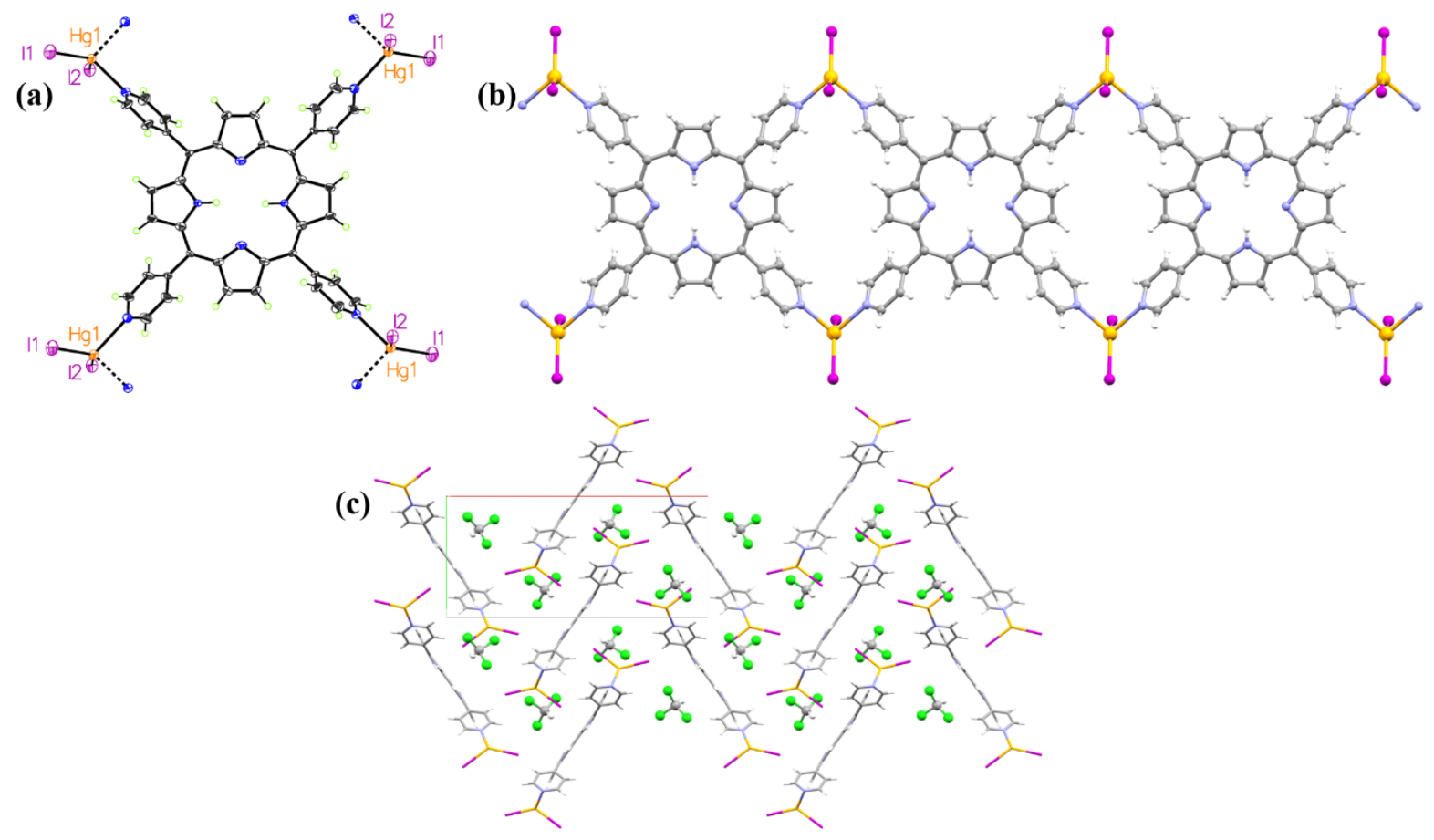

Figure 1. (a) $50 \%$ Probability ellipsoid plot of 1; heavy dashed lines indicate extension of coordination polymer. (b) View of the one-dimensional coordination polymer formed by 1. (c) View down the $c$-axis showing the near-orthogonal herringbone packing of chains, with solvent molecules residing in small gaps along the chains.

The overall structure of the coordination polymer is similar to several of those previously reported,,$^{10,1316-17}$ but with a different packing arrangement of the chains. Instead of the planes of the porphyrin rings in adjacent chains being coplanar, the stacking of chains is offset, and adjacent stacks of chains pack nearly orthogonally. Due to this offset, adjacent TPyP molecules are too far apart to take part in $\pi$-stacking interactions; the closest approach is between the edges of two pyrrole rings at 5.74(1) $\AA$ (distances of less than $3.6 \AA$ are expected for true interactions) $)^{98}$. In contrast to many of the one-dimensional polymers of this type formed from TPyP, where solvent-filled regions form between stacked chains, ${ }^{18}$ no such solvent domains are formed in the 
structure, and the ordered $\mathrm{CHCl}_{3}$ and disordered TCE solvent molecules reside in the individual gaps between adjacent chains (Figure 1c).

No strong interactions were found to occur between the $\mathrm{CHCl}_{3}$ solvent molecules and the polymeric chains, with no contacts between them within the sum of the van der Waals' radii.

This is unexpected, as these solvent molecules were seen to be fully ordered within the structure. As no topologically significant, strong and directional interactions take place between polymeric chains to create a two- or three-dimensional network, the topology of $\mathbf{1}$ is simply that of a metallamacrocyclic chain.

This arrangement of chains can be considered as a herringbone packing motif when viewed down the $c$-axis (Figure 1c). Such a motif has been seen previously in a TPyP coordination polymer formed with $\mathrm{HgBr}_{2},{ }^{14}$ however there are significant differences between the packing of these two structures. In the $\mathrm{HgBr}_{2}$ structure, orthogonal chains pack such that the $\mathrm{HgBr}_{2}$ linker of one chain interdigitates into the metallamacrocyclic ring of the next and forms interactions with the $\mathrm{HgBr}_{2}$ linkers of that ring. In contrast, in 1 no interdigitation occurs between chains, instead, the $\mathrm{HgI}_{2}$ groups are positioned so that an interaction may be seen between one $\mathrm{I}^{-}$anion and a

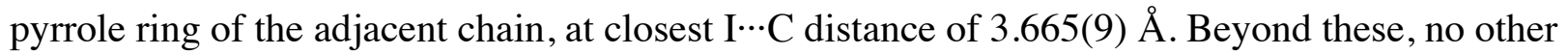
interactions take place between adjacent chains.

\section{Structure of $\left.\left\{\mathrm{Ba}(\mu 1,1-\mathrm{NCS})(\mu 1,1,3-\mathrm{NCS})\left(\mathrm{H}_{2} \mathrm{O}\right)(\mathrm{MeCN})\right)_{2}(\mathrm{TPyP})\right\}_{n} \cdot 4 n \mathrm{H}_{2} \mathrm{O}$ (2). Compound 2,} formed from the reaction of TPyP and $\mathrm{Ba}(\mathrm{SCN})_{2} \cdot 3 \mathrm{H}_{2} \mathrm{O}$, crystallized in the triclinic space group $P \overline{1}$. The asymmetric unit consists of one eight-coordinate $\mathrm{Ba}(\mathrm{II})$ cation, two $\mathrm{SCN}-$ anions, half a molecule of TPyP, a coordinated MeCN solvent molecule, and three water molecules, one of 
which is coordinated (Figure 2a). The centroids of the porphyrin ring and of the SCN-bridged Ba dimers are found on a centers of symmetry.
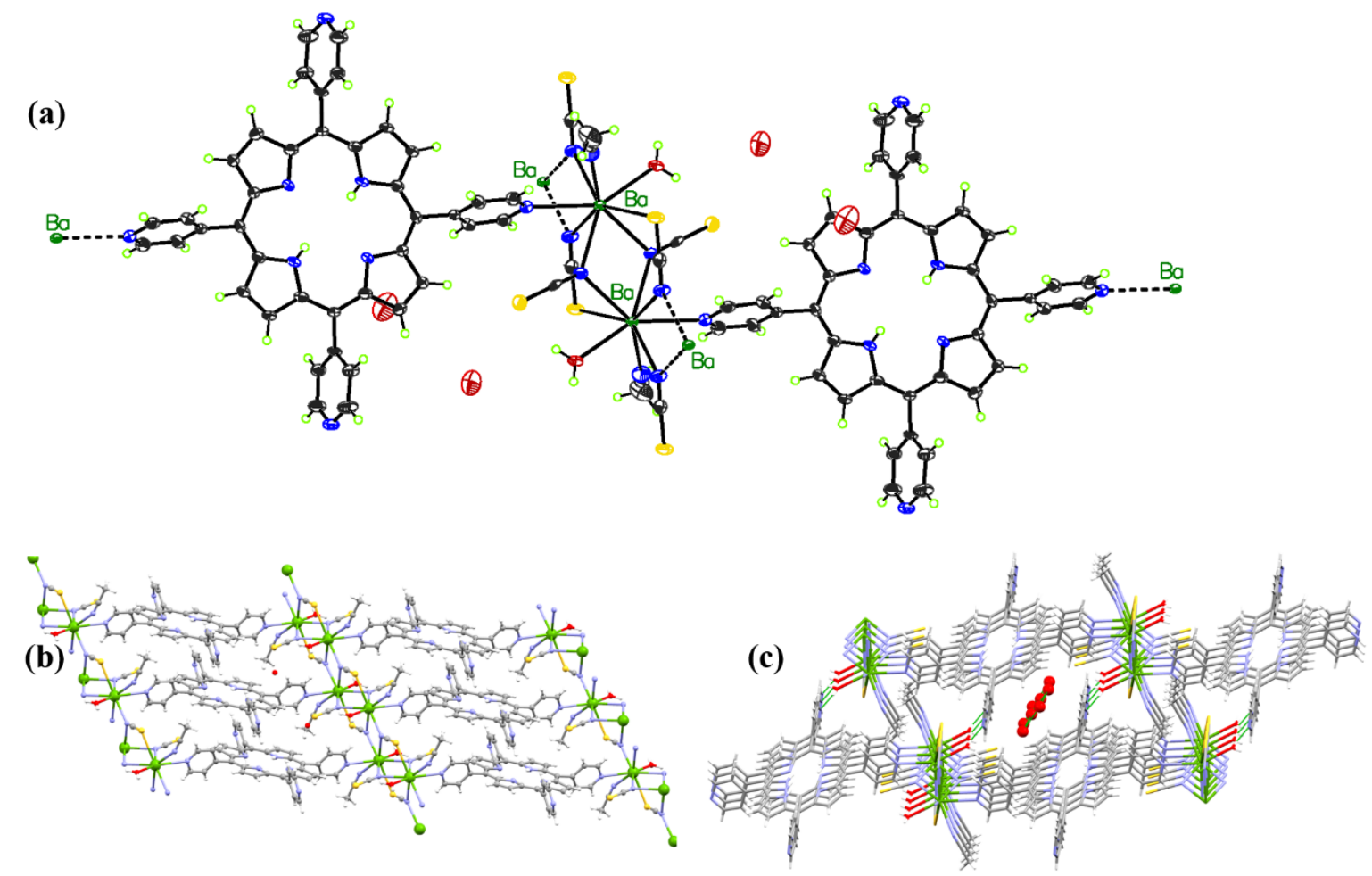

Figure 2. (a) $50 \%$ probability ellipsoid plot of 2 ; heavy dashed lines indicate extension of coordination polymer. (b) View along the $a$-axis of the two-dimensional coordination polymer, with non-coordinated water molecules omitted. (c) View down the $c$-axis of the three-dimensional hydrogen bonded net of 2; dashed green lines indicate strong hydrogen bond vectors.

The structure of $\mathbf{2}$ is a particularly intricate, hierarchical 3D network comprised of inorganic onedimensional polymers crosslinked in two orthogonal directions by different interactions with the TPyP moieties. First, the square-antiprismatic Ba(II) coordination polyhedra form infinite edgesharing chains bridged directly by $\mu^{2}$-thiocyanate nitrogen atoms. The sulfur atom of one thiocyanate group further links these by coordinating to a separate $\mathrm{Ba}$ (II) center from the 
nitrogen atom, as observed in the structure of $\mathrm{K}_{2} \mathrm{Mg}_{2}(\mathrm{SCN})_{6} \cdot 3 \mathrm{H}_{2} \mathrm{O} .{ }^{99}$ These one-dimensional $\mathrm{Ba}(\mathrm{SCN})_{2}$ tapes run along the crystallographic $c$-axis and are linked along the $\left(\begin{array}{lll}0 & 1 & 1\end{array}\right)$ plane by coordination to trans pyridine groups of the TPyP. (Figure $2 \mathbf{b}$ ). In this structure the porphyrin cores of the TPyP rings do not lie in the plane of the two-dimensional sheets but are tilted out of the plane so that the non-coordinating pyridine rings are pointed parallel to the $\left(\begin{array}{lll}0 & -1 & 1\end{array}\right)$ plane. These groups accept strong hydrogen bonds from coordinating water molecules generating the overall three-dimensional network. Finally, the networks contain small pores running along the $a$-axis which appear to be occupied by cyclic tetramers of hydrogen bonded water molecules.

The topology of the two-dimensional coordination polymeric net could be defined as a uninodal $6^{3}$, or honeycomb, hcb net, ${ }^{100}$ with nodes based on the Ba(II) cations (Figure 2c). Each node is linked to three other nodes, two via the links of the SCN- anions, the other via the coordinated TPyP. Compound $\mathbf{2}$ is the first TPyP-containing structure to show the $6^{3}$ topology. It is also the second two-dimensional TPyP-containing structure where TPyP behaves as a simple linker, rather than as a four-connected node. ${ }^{s 8}$ This is likely due to the structural flexibility afforded to this type of linkage. The TPyP molecule can rotate freely about the axis passing through the C-C single bonds that connect the coordinating pyridine groups to the porphyrin core without perturbing the $\mathrm{Ba}(\mathrm{II})$ coordination environment. Similarly, the coordinated water molecule can rotate freely about the O-Ba bond axis and donate hydrogen bonds anywhere along the cone described the rotation of the $\mathrm{O}-\mathrm{H}$ bonds about this axis.

When the hydrogen bonds between non-coordinated pyridine rings and $\mathrm{H}_{2} \mathrm{O}$ molecules are taken into account, the resulting three-dimensional net is topologically more complex. The net becomes four-connected, comprising two topologically different nodes, one based on the centroid of the TPyP ligand, the other on the Ba(II) ions. The TPyP nodes are linked to four 
different $\mathrm{Ba}$ nodes via coordination of two pyridines, and hydrogen bonding between the other two pyridines and $\mathrm{H}_{2} \mathrm{O}$. The Ba nodes in turn are linked in a similar fashion to two different TPyP nodes, one by coordination, the other by hydrogen-bonding, and to two further Ba nodes via the bridging $\mathrm{SCN}-$ ligands. The short topological term of the TPyP nodes is, $4^{2} .6^{2} .8^{2}$, while for the Ba nodes it is $4.6^{4} \cdot 8$. This results in an overall network topology of $\left(4.6^{4} \cdot 8\right)_{2} \cdot\left(4^{2} \cdot 6^{2} \cdot 8^{2}\right)$. This particular net is also known as the moganite ( $\mathbf{m o g}$ ) net, ${ }^{100}$ and it is uncommon among coordination polymers, with only eight compounds described in their reports as having it. ${ }^{102}$ Databases within the Reticular Chemistry Structural Resource (RCSR) ${ }^{100}$ and within the Topos ${ }^{10}$ software package indicate that a few more unrecognized instances of the network have been found, with around 35 other structures exhibiting the mog net in total and the closest related to $\mathbf{2}$ being a coordination polymer composed of $\left[\mathrm{Dy}\left(\mathrm{C}_{2} \mathrm{O} 4\right)_{2}\left(\mathrm{OH}_{2}\right)_{2}\right]_{\text {c }}$ chains linked by tetrakis(3-carboxyphenyl)porphyrin zwitterions."'!

Structure of $\left[\mathbf{H}_{3} \mathbf{T P y P}\right]\left[\mathrm{PF}_{6}\right]_{3} \cdot \mathbf{0 . 5 T C E}(\mathbf{3})$. Compound 3 was formed spontaneously from the 1:2 molar reaction of TPyP and $\mathrm{AgPF}_{6}$ in TCE-MeOH. It crystallized in the monoclinic space group $P 2 / / c$, and the asymmetric unit consists of half of a $\left[\mathrm{H}_{3} \mathrm{TPyP}\right]^{3+}$ cation, protonated with $75 \%$ occupancy on both unique pyridine $\mathrm{N}$ atoms, one ordered $\left[\mathrm{PF}_{6}\right]$ anion, one half of an ordered $\left[\mathrm{PF}_{6}\right]$ anion located on a special position, and disordered solvent (determined to consist of half a molecule of TCE per $\left[\mathrm{H}_{3} \mathrm{TPyP}\right]^{3+}$ cation using the SQUEEZE routine in PLATON $\left.{ }^{s}\right)$. The $\left[\mathrm{H}_{3} \mathrm{TPyP}\right]^{3+}$ ion and one of the $\left[\mathrm{PF}_{6}\right]$ ions reside on crystallographic inversion centers (Figure 3a). Further checks were conducted to ensure that the unmodeled solvent was not in fact another $\left[\mathrm{PF}_{6}\right]$ anion; however the number of electrons removed was not sufficient for that to be the case, and earlier attempts to model the disordered species suggested TCE, rather than $\left[\mathrm{PF}_{6}\right]$ to be present. Interestingly the reaction of $\mathrm{AgPF}_{6}$ with $\mathrm{TPyP}$ in this solvent system has been reported to 
produce the expected coordination polymer when conducted at $-10{ }^{\circ} \mathrm{C} .{ }^{15} \mathrm{We}$ suspect that at room temperature, atmospheric water vapor provides a source of adventitious $\mathrm{H}^{+}$which leads to the formation of a salt that is apparently more stable than the coordination polymer.

(a)

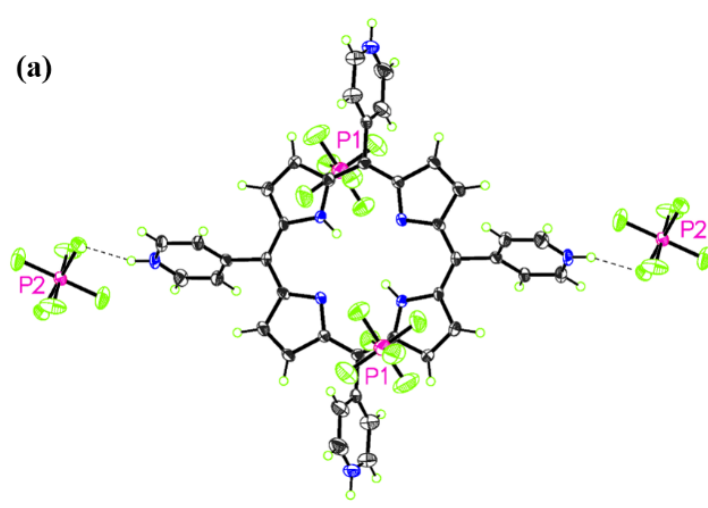

(c)

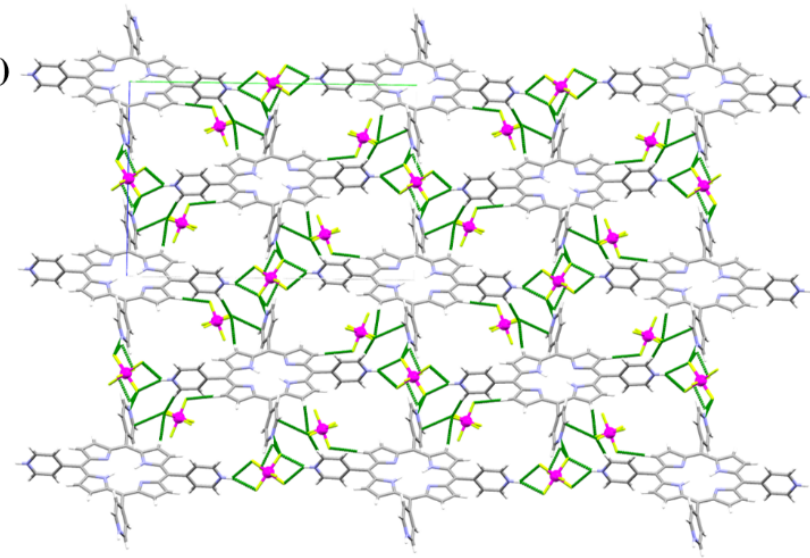

(b)

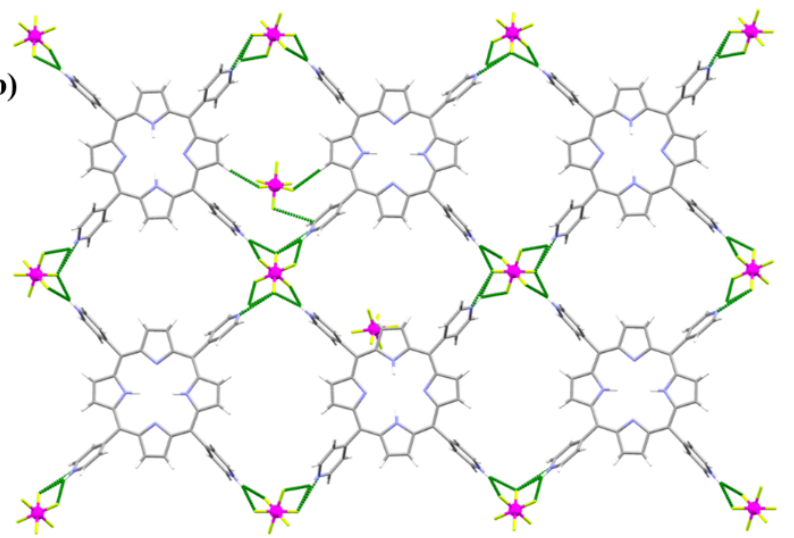

Figure 3. $50 \%$ Probability ellipsoid plot of 3. (b) Two-dimensional, hydrogen bonded network lying in the (1 0 2) plane. (c) 2x2x2 unit cell packing diagram viewed along $a$-axis. Dashed green lines indicate especially short contacts (at least 0.2 A shorter than the sum of the Van der Waals radii). Disordered $\mathrm{H}$ atoms shown distributed across all sites.

Hydrogen bonds form between both of the unique, partially protonated pyridines and one of the $\left[\mathrm{PF}_{6}\right]$ anions. In both cases a bifurcated interaction results, with $\mathrm{N}-\mathrm{H} \cdots \mathrm{F}$ donor-acceptor 
distances ranging from $2.877(3)$ to 2.931 (4) $\AA$. Further short contacts also occur between the anions and the aromatic hydrogens of the $\left[\mathrm{H}_{3} \mathrm{TPyP}\right]^{3+}$ cations, with $\mathrm{C}-\mathrm{H} \cdots \mathrm{F}$ donor-acceptor distances ranging from 3.137(4) to 3.299(4) $\AA$. The combination of the two sets of hydrogen bonding interactions gives rise to a two-dimensional network, formed in the $\left(\begin{array}{lll}1 & 0 & 2\end{array}\right)$ plane, although the specific nature of this net is complicated by the partial occupancies of the protons bound to the pyridine $\mathrm{N}$ atoms (Figure $3 \mathbf{b}$ ).

Packing of adjacent sheets occurs such that parallel $\left[\mathrm{H}_{3} \mathrm{TPyP}\right]^{3+}$ cations are diagonally offset by approximately half the length of the molecule, with a pyridine ring of one residing above the central cavity of the $\left[\mathrm{H}_{3} \mathrm{TPyP}\right]^{3+}$ of the other. This packing arrangement causes the $\left[\mathrm{H}_{3} \mathrm{TPyP}\right]^{3+}$ cations to stack, although the shortest distance (3.962 A between carbon atoms of two pyrrole rings) is too long to indicate an interaction. The $\left[\mathrm{PF}_{6}\right]$ anion not involved in strong $\mathrm{H}$ bonding is positioned to form anion $\cdots \pi$ interactions within pockets formed by two protonated pyridines and one pyrrole ring, where F- groups make short contacts to atoms on each of these rings that are perpendicular to the ring plane. These interactions anchor the anions in the centers of these pockets. The packing arrangement gives rise to small pores within the structure running along the crystallographic $a$-axis which are occupied by the disordered solvent molecules.

Topological analysis of the two-dimensional sheets was complicated by the fact that the pyridine rings are only protonated with partial occupancy. However, since investigation of the difference Fourier map did not indicate preference for protonation at one $\mathrm{N}$ site over any other, the analysis was conducted as if the protonation had been complete. The topology was found to be that of a four-connected net, comprising two different nodes, one based on the centroid of the $\left[\mathrm{H}_{3} \mathrm{TPyP}\right]^{3+}$ cation, the other on the $\mathrm{P}$ atom of the $\left[\mathrm{PF}_{6}\right]$ anion. Each node is linked to four other nodes via the 
hydrogen bonds formed between $\left[\mathrm{H}_{3} \mathrm{TPyP}\right]^{3+}$ and $\left[\mathrm{PF}_{6}\right]$. This results in each node having the short topological term $4^{4} \cdot 6^{2}$, more commonly known as a square grid $(\mathbf{s q l})$ or $(4,4)$ net. ${ }^{101}$

Structure of $\left[\mathrm{H}_{2} \mathrm{TPyP}\right]\left[\mathrm{I}_{3}\right]_{2} \cdot 2 \mathrm{MeOH}(4)$. Compound 4 was formed spontaneously from the reaction of TPyP and $\mathrm{CrI}_{3}$, and crystallized in the triclinic space group $P \overline{1}$. The asymmetric unit consists of half of a $\left[\mathrm{H}_{2} \mathrm{TPyP}\right]^{2+}$ cation, two half, ordered $\mathrm{I}_{3}^{-}$anions, and a MeOH molecule (Figure 4a). The centroid of the porphyrin ring lies on a center of symmetry. The oxidation of the $\mathrm{I}^{-}$anions to $\mathrm{I}_{3}^{-}$observed here was also observed in the formation of another porphyrinic salt, $\left(\mathrm{H}_{4} \mathrm{TPyP}\right) \mathrm{Cl}_{2}\left(\mathrm{I}_{3}\right)_{2}{ }^{38}$

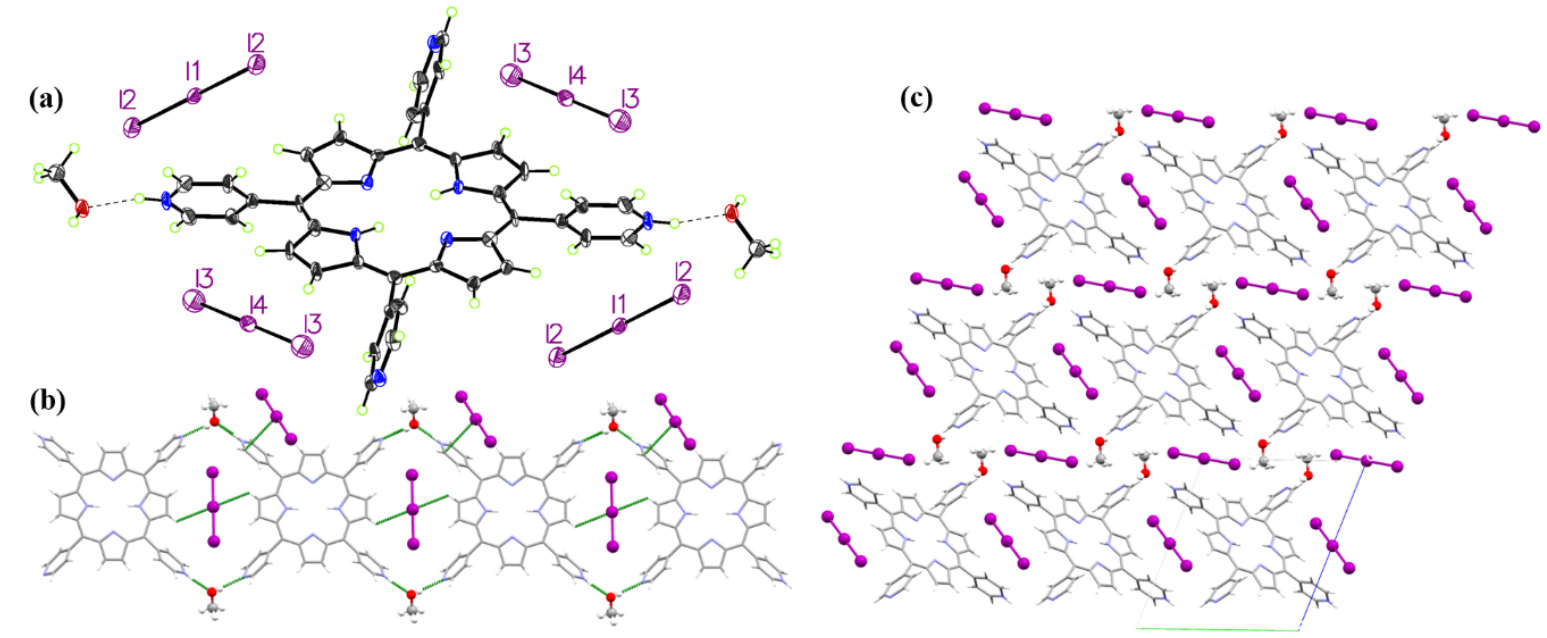

Figure 4. (a) $50 \%$ Probability ellipsoid plot of 4. (b) One-dimensional hydrogen bonded chains viewed along the crystallographic $a b$-diagonal. (c) $2 \times 2 \times 2$ unit cell packing diagram viewed down a. Dashed green lines indicate short (less than the sum of the Van der Waals radii) contacts.

Protonated pyridine sites donate hydrogen bonds to lattice $\mathrm{MeOH}$ molecules, and these $\mathrm{MeOH}$ molecules then donate hydrogen bonds to the free base pyridine groups $(\mathrm{N}-\mathrm{H} \cdots \mathrm{O}$ and $\mathrm{O}-\mathrm{H} \cdots \mathrm{N}$ 
donor-acceptor distances are 2.68(1) and 2.78(1) $\AA$, respectively). The combination of the two sets of hydrogen bonding interactions gives rise to one-dimensional hydrogen bonded macrocyclic chains of $\left[\mathrm{H}_{2} \mathrm{TPyP}\right]^{2+}$ cations and $\mathrm{MeOH}$ molecules, running along the crystallographic $a b$ diagonal (Figure $\mathbf{4 b}$ ). The $\mathrm{I}_{3}$ anions are in turn held in place in the structure by weak interactions with the aromatic $\mathrm{C}-\mathrm{H}$ groups of the $\left[\mathrm{H}_{2} \mathrm{TPyP}\right]^{2+}$ cations, at a $\mathrm{C}-\mathrm{H} \cdots \mathrm{I}$ donoracceptor distance of 3.966(8) A. As no topologically significant, strong and directional interactions take place between the hydrogen bonded chains to create a two- or threedimensional network, the topology of $\mathbf{4}$ is simply that of a macrocyclic chain.

The chains pack such that individual $\left[\mathrm{H}_{2} \mathrm{TPyP}\right]^{2+}$ cations are diagonally offset from each other by approximately half the length of the molecule, with a pyridine ring of one residing above the central cavity of the $\left[\mathrm{H}_{2} \mathrm{TPyP}\right]^{2+}$ of the other, in a similar fashion to that seen in $\mathbf{3}$. However, in this structure, the additional presence of the bulky $\mathrm{I}_{3}^{-}$anions result in the $\left[\mathrm{H}_{2} \mathrm{TPyP}\right]^{2+}$ cations not approaching each other as closely as was seen for $\mathbf{3}$. While the packing arrangement does cause pyrrole rings to stack parallel to each other (with the angle between ring planes being $2.7(4)^{\circ}$ ), the distance is too long to indicate an interaction. In addition, one of the pyridine rings is positioned so that one $\mathrm{C}-\mathrm{H}$ group can form a $\mathrm{C}-\mathrm{H} \cdots \pi$ interaction with a pyrrole ring of a neighboring $\left[\mathrm{H}_{2} \mathrm{TPyP}\right]^{2+}$ cation, with the shortest donor-acceptor distance $\left(\mathrm{C}-\mathrm{H}_{\text {pridion }}{ }^{\cdots} \mathrm{N}_{\text {promel }}\right)$ being 3.38(1) A. This packing motif allows for the formation of small channels running down the crystallographic $a$-axis, which are occupied by the $\mathrm{I}_{3}^{-}$anions (Figure $4 \mathbf{c}$ ). These pores are formed in two areas; beside the macrocyclic hydrogen-bonded ring, and beside the slightly interdigitated arrangement of the $\mathrm{MeOH}$ molecules, which creates discrete gaps between hydrogen bonded chains. 
Structure of $\left[\mathrm{H}_{4} \mathrm{TPyP}\right]\left[\mathrm{UO}_{2} \mathrm{Cl}_{4}\right]_{2} \cdot \mathbf{6 M e C N}(5)$. Compound 5 , formed from the reaction of TPyP and $\mathrm{UO}_{2} \mathrm{Cl}_{2} \cdot 3 \mathrm{H}_{2} \mathrm{O}$, crystallized in the triclinic space group $P \overline{1}$. The asymmetric unit consists of half of a $\left[\mathrm{H}_{4} \mathrm{TPyP}\right]^{4+}$ cation, one $\left[\mathrm{UO}_{2} \mathrm{Cl}_{4}\right]^{2-}$ complex anion, and three molecules of $\mathrm{MeCN}$ arranged around a crystallographic inversion center located at the centroid of the TPyP cation. The $\left[\mathrm{UO}_{2} \mathrm{Cl}_{4}\right]^{2}$ has the expected geometry in which four $\mathrm{Cl}$ ligands are arranged equatorially around the trans-[UO $]^{2+}$ center. One set of hydrogen bonds occurs between one of the unique protonated pyridine rings and one of the unique $\mathrm{MeCN}$ solvent molecules, with a $\mathrm{N}-\mathrm{H} \cdots \mathrm{N}$ donor-acceptor distance of 2.80(1) A. The other set of hydrogen bonds occurs between the remaining unique protonated pyridine and one of the $\mathrm{Cl}$ ligands of the $\left[\mathrm{UO}_{2} \mathrm{Cl}_{4}\right]^{2}$ anion, with a $\mathrm{N}-\mathrm{H} \cdots \mathrm{Cl}$ donoracceptor distance of 3.249(7) $\AA$. These two sets of interactions give rise to the formation of discrete dinuclear hydrogen-bonded complexes, comprising one $\left[\mathrm{H}_{4} \mathrm{TPyP}\right]^{4+}$ cation, two $\left[\mathrm{UO}_{2} \mathrm{Cl}_{4}\right]^{2}$ anions, and two molecules of MeCN (Figure 5a). The anions and solvent are further held in place by other weaker interactions with the cation, via a variety of $\mathrm{C}-\mathrm{H} \cdots \mathrm{N}, \mathrm{C}-\mathrm{H} \cdots \mathrm{O}$, and $\mathrm{C}-$ $\mathrm{H} \cdots \mathrm{Cl}$ interactions, with $\mathrm{C}-\mathrm{H} \cdots$ acceptor distances of 2.46 to $2.65 \AA$, and C $\cdots$ acceptor separations of $3.249(7)$ to $3.538(11) \AA$. 

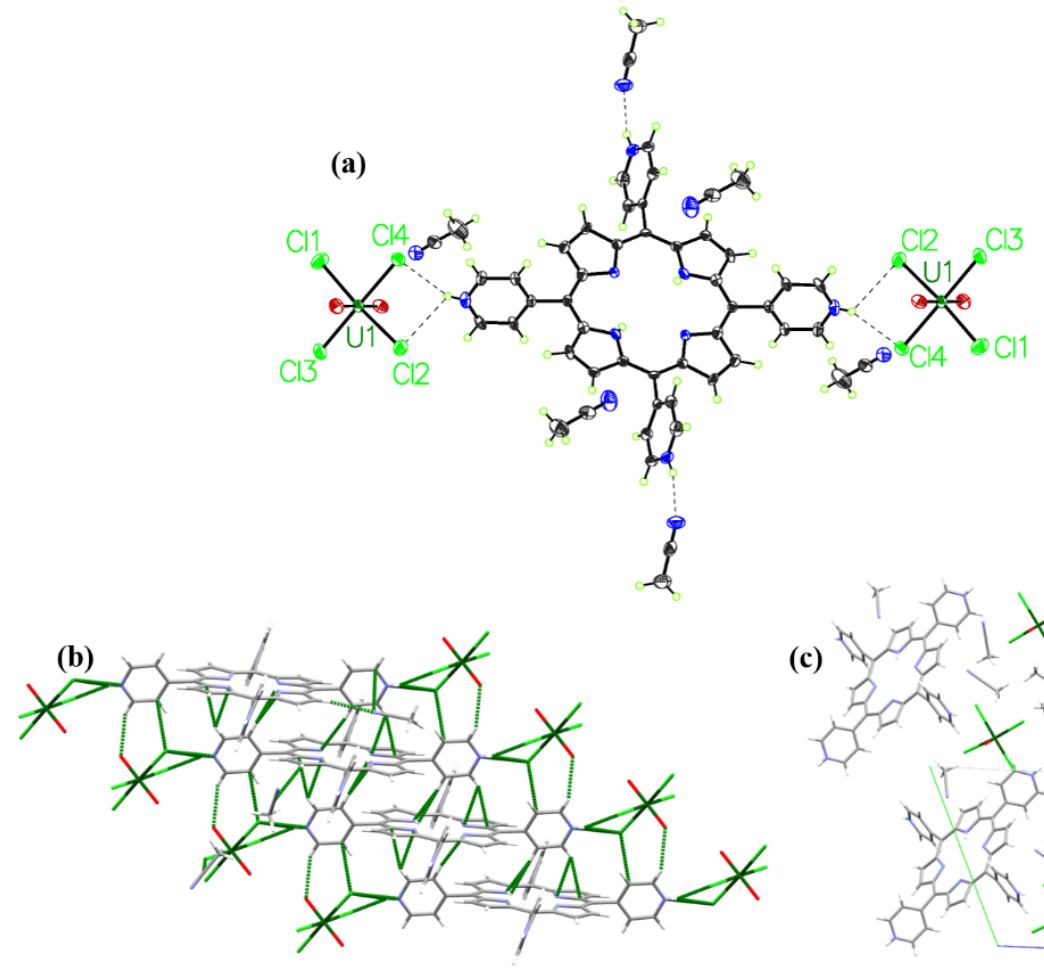

(c)

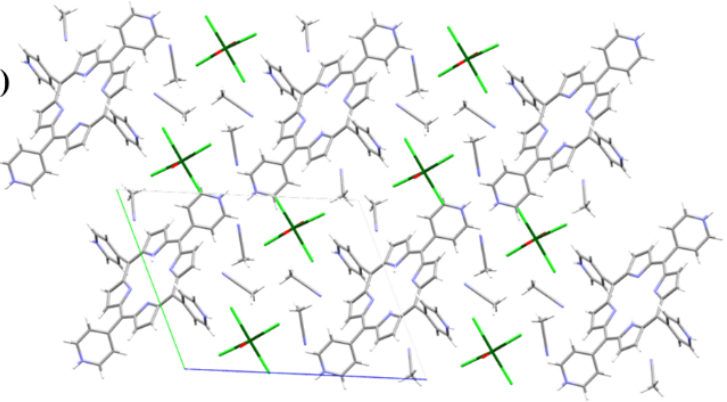

Figure 5. (a) $50 \%$ Probability ellipsoid plot of 5. (b) Stacking of discrete hydrogen bonded moieties. (c) $2 \times 2 \times 2$ unit cell packing diagram viewed down $a$. Dashed green lines indicate short (less than the sum of the van der Waals radii) contacts.

The interactions within 5 result in a packing of adjacent $\left[\mathrm{H}_{4} \mathrm{TPyP}\right]^{++}$cations similar to those seen in $\mathbf{3}$ and 4, with a diagonal offset from each other by approximately half the length of the TPyP molecule, with a pyridine ring of one residing above the central cavity of the $\left[\mathrm{H}_{4} \mathrm{TPyP}\right]^{4+}$ of the other (Figure 5b). These rings form infinite stacks along the $a$ axis, consequently organizing the anions into columns and creating channels along $a$ filled by $\mathrm{MeCN}$ molecules (Figure 5c). As was the case in $\mathbf{4}$, the large anions prevent the formation of strong $\pi-\pi$ interactions, with only a weak interaction occurring between adjacent pyrrole rings, with a centroid $\cdots$ centroid distance of $3.805(5) \AA$, and an angle between ring planes of 5.3(5) . Once again, another set of $\pi$ 
interactions are found to occur, where the protonated pyridine rings form weak $\pi \cdots$ anion interactions with one of the chlorides of the $\left[\mathrm{UO}_{2} \mathrm{Cl}_{4}\right]^{2}$ anions.

As no topologically significant, strong and directional interactions take place between the hydrogen bonded dinuclear species to create a network, the topology of $\mathbf{5}$ is simply that of a dinuclear hydrogen-bonded complex. The presence of a large number of potential hydrogen bond acceptors in $\mathbf{5}$ means that rather than one acceptor species being able to form a hydrogenbonded bridge between two protonated porphyrins, four discrete hydrogen bonds are formed. This results in the formation of the very unusual discrete hydrogen bonded complex. This is only the sixth discrete hydrogen bonded complex of TPyP that has been structurally characterized; the other five being hydrogen bonded clathrates between non-protonated TPyP and either acetic acid, ${ }^{54}$ or substituted phenols. ${ }^{112}$

Structure of $\left[\mathrm{H}_{4} \mathrm{TPyP}\right]\left[\mathrm{Th}\left(\mathrm{NO}_{3}\right)_{6}\right]\left[\mathrm{NO}_{3}\right]_{2}(6)$. Compound 6 was formed from the reaction of TPyP and $\mathrm{Th}\left(\mathrm{NO}_{3}\right)_{4} \cdot 5 \mathrm{H}_{2} \mathrm{O}$, and crystallized in the monoclinic space group $\mathrm{C} 2 / c$. The asymmetric unit consists of half a $\left[\mathrm{H}_{4} \mathrm{TPyP}\right]^{++}$cation, protonated at both pyridine rings, one $\left[\mathrm{Th}\left(\mathrm{NO}_{3}\right)_{6}\right]^{2}$ complex anion, and two non-coordinated $\left[\mathrm{NO}_{3}\right]$ anions (Figure 6a). The centroid of the porphyrin ring lies on a center of symmetry. $\left[\mathrm{Th}\left(\mathrm{NO}_{3}\right)_{6}\right]^{2}$ is composed of a twelve-coordinate Th(IV) ion center ligated by exclusively bidentate $\left[\mathrm{NO}_{3}\right]$ groups resulting in a slightly distorted icosahedral coordination geometry typical for this species. ${ }^{113}$ Unlike complexes 1-5, complex 6 does not contain any incorporated solvent molecules. 


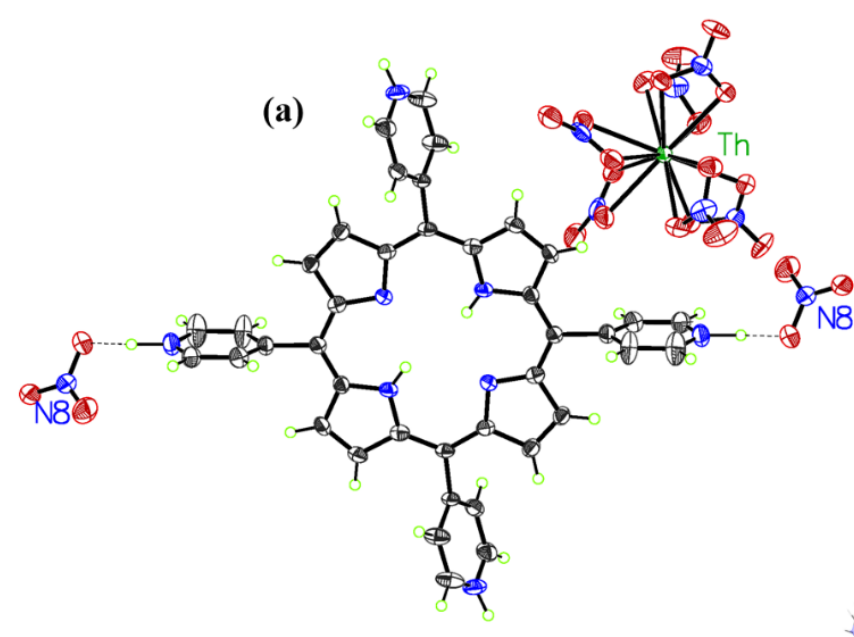

(b)
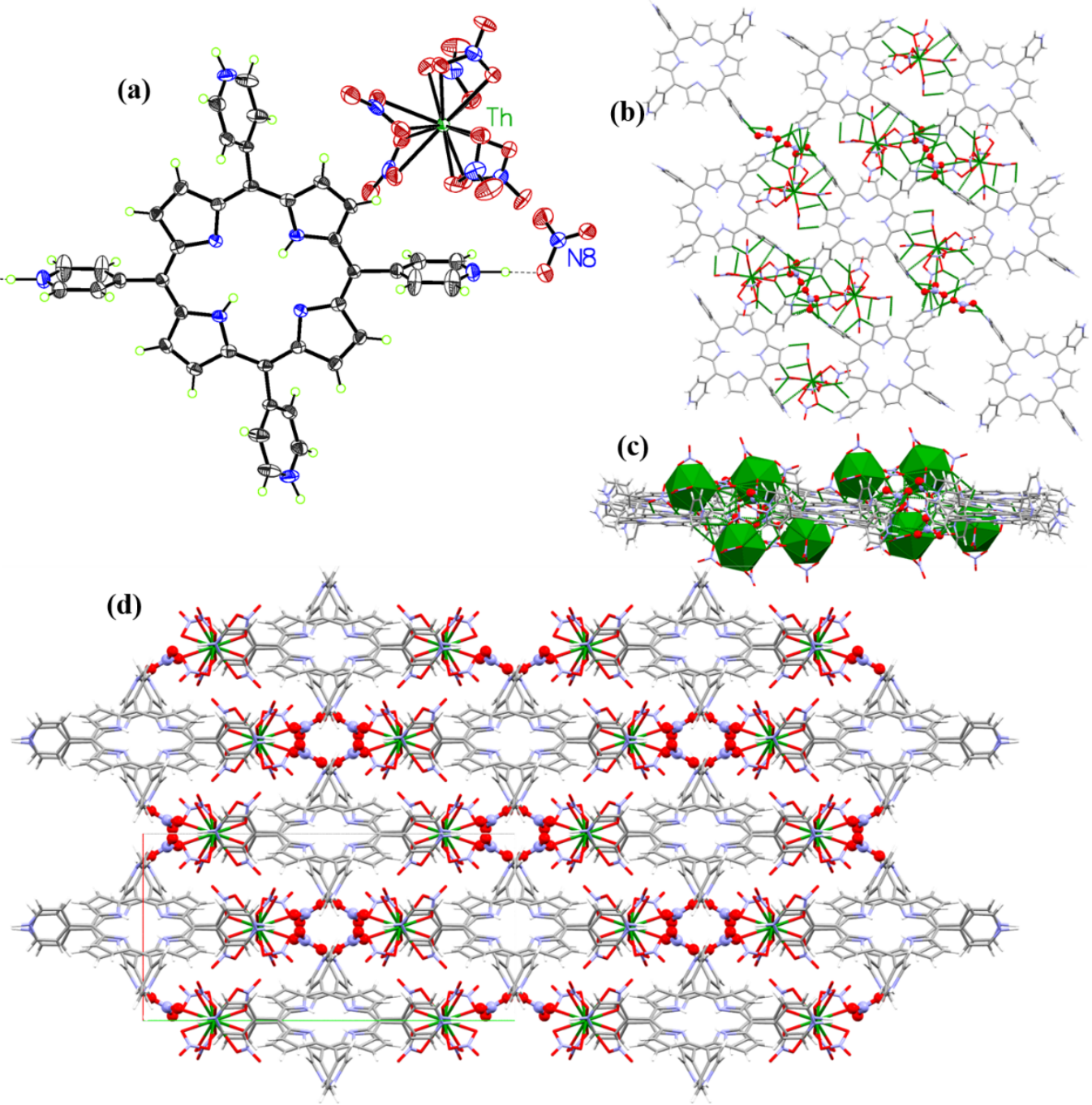

Figure 6. (a) 50\% Probability ellipsoid plot of 6. (b, c) Views perpendicular to and along hydrogen bonded sheets, respectively. (d) 2x2x2 unit cell packing diagram viewed down $c$. Dashed green lines indicate short (less than the sum of the Van der Waals radii) contacts.

Three sets of hydrogen bonds form in complex $\mathbf{6}$. All of these are between the protonated pyridine rings and the non-coordinated $\left[\mathrm{NO}_{3}\right]$ anions, with one pyridine forming a pair of hydrogen bonds to two $\mathrm{O}$ atoms on the same $\left[\mathrm{NO}_{3}\right]$ anion. These hydrogen bonds have $\mathrm{N}-\mathrm{H} \cdots \mathrm{O}$ donor-acceptor distances ranging from 2.676(7) to 3.157(7) $\AA$. The combination of these hydrogen bonds gives rise to a two-dimensional hydrogen-bonded sheet, which resides in the (1 
0 -1) plane (Figure 6b). The $\left[\mathrm{Th}\left(\mathrm{NO}_{3}\right)_{6}\right]^{2-}$ anions form a number of weaker $\mathrm{C}-\mathrm{H} \cdots \mathrm{O}$ interactions with the cations which occur at $\mathrm{C}-\mathrm{H} \cdots \mathrm{O}$ donor-acceptor distances from 2.984(7) to 3.435(7) $\AA$. The bulky anions reside in the gaps between adjacent $\left[\mathrm{H}_{4} \mathrm{TPyP}\right]^{4+}$ cations, but out of the plane of the hydrogen bonded sheets. The positioning of the anions results in distortions of adjacent sheets in order to accommodate them, with all $\left[\mathrm{H}_{4} \mathrm{TPyP}\right]^{++}$cations being inclined slightly out of the plane of the sheets (Figure 6c).

The packing of sheets is again similar to that seen for $\mathbf{3}-\mathbf{5}$, with a diagonal offset of individual $\left[\mathrm{H}_{4} \mathrm{TPyP}\right]^{++}$cations of approximately half the length of the molecule where a pyridine ring of one resides above the central cavity of the $\left[\mathrm{H}_{4} \mathrm{TPyP}\right]^{++}$of the other. One of the pyridine rings of the $\left[\mathrm{H}_{4} \mathrm{TPyP}\right]^{4+}$ cation is positioned so that it can form a $\mathrm{C}-\mathrm{H} \cdots \pi$ interaction with a pyrrole ring of a neighboring $\left[\mathrm{H}_{4} \mathrm{TPyP}\right]^{++}$, with a $\mathrm{C}-\mathrm{H} \cdots \mathrm{N}$ donor-acceptor distance of $3.465 \AA$. As was seen for 4 and $\mathbf{5}$, the distortions within the hydrogen bonded sheets caused by the large anions prevent the formation of any stronger $\pi-\pi$ interactions, the shortest centroid $\cdots$ centroid distance between parallel $\left[\mathrm{H}_{4} \mathrm{TPyP}^{4+}\right.$ groups being $3.938(3) \AA$.

The topology of the hydrogen-bonded sheets was again found to be a four-connected sql net. ${ }^{101}$ However, in 6 there is only one type of node, based on the $\left[\mathrm{H}_{4} \mathrm{TPyP}\right]^{4+}$ moiety (in other structures, such as $\mathbf{3}$, the anion can also act as a node). Also, due to the presence of the bulky $\left[\mathrm{Th}\left(\mathrm{NO}_{3}\right)_{6}\right]^{2-}$ anions between the sheets the positioning of the connecting $\left[\mathrm{NO}_{3}\right]$ anions diverges significantly from the ideal position of centroid-centroid connectors. This degree of distortion away from the idealized net-form has not previously been seen in TPyP-containing sql nets. 


\section{Structure of $\mathrm{Ce}\left(\mathrm{NO}_{3}\right)_{3}(\mathrm{MeOH})_{3}\left(\mathrm{H}_{2} \mathrm{O}\right) \cdot(\mathrm{TPyP}) \cdot \mathbf{T C E} \cdot \mathrm{H}_{2} \mathrm{O}(\mathbf{7})$. Compound 7 was formed}

spontaneously from the reaction of TPyP and $\mathrm{Ce}\left(\mathrm{NO}_{3}\right)_{3} \cdot 6 \mathrm{H}_{2} \mathrm{O}$ in TCE/MeOH. The resulting neutral complex crystallized in the monoclinic space group $P 2{ }_{1}$ twinned by a rotation mapping $c$ onto the $a c$ diagonal (see experimental). The asymmetric unit consists of a neutral TPyP molecule, a neutral $\mathrm{Ce}\left(\mathrm{NO}_{3}\right)_{3}(\mathrm{MeOH})_{3}\left(\mathrm{H}_{2} \mathrm{O}\right)$ complex, and one molecule each of non-coordinated TCE and $\mathrm{H}_{2} \mathrm{O}$ (Figure 7a). The Ce(III) ion has a ten-coordinate geometry which can be described as a bicapped square antiprism, with two bidentate $\left[\mathrm{NO}_{3}\right]$ ligands occupying both capping and regular sites.

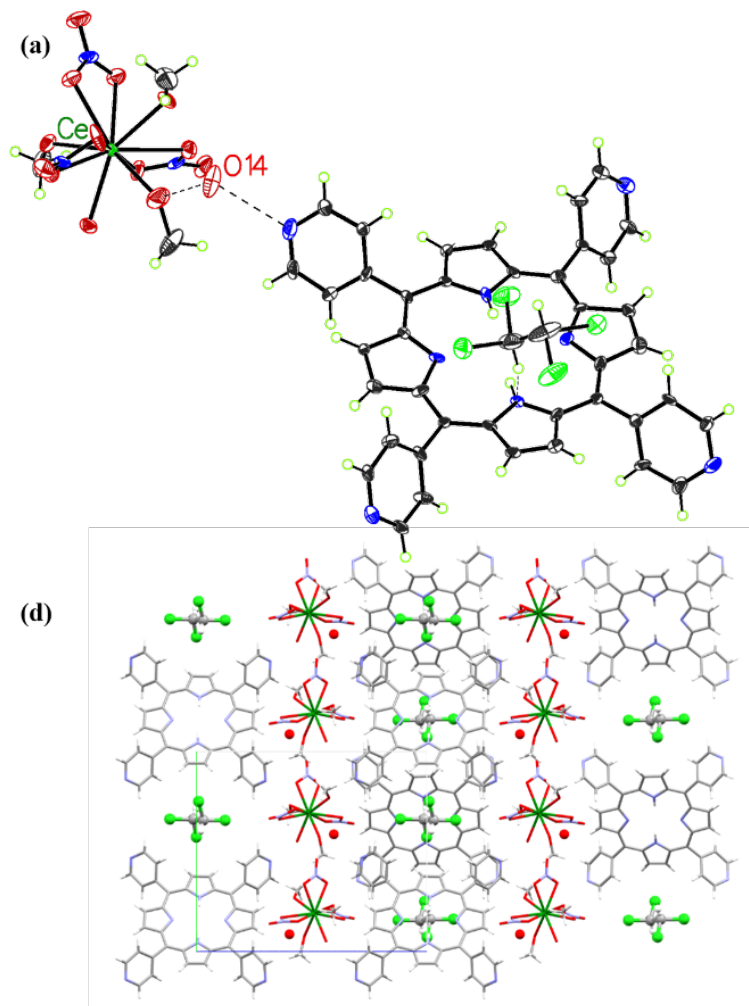

(b)

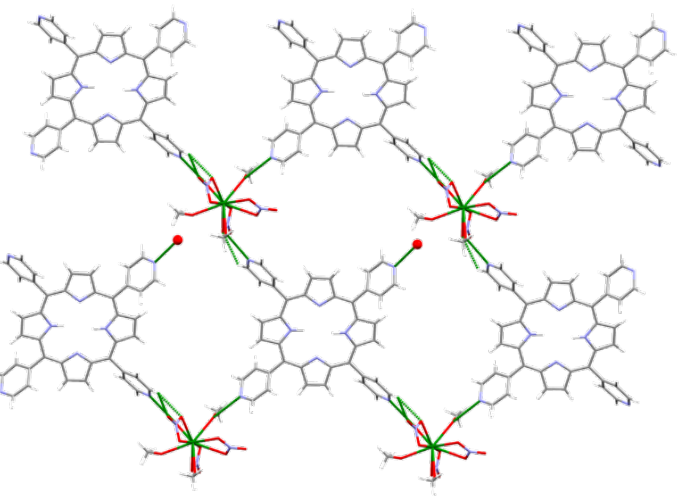

(c)

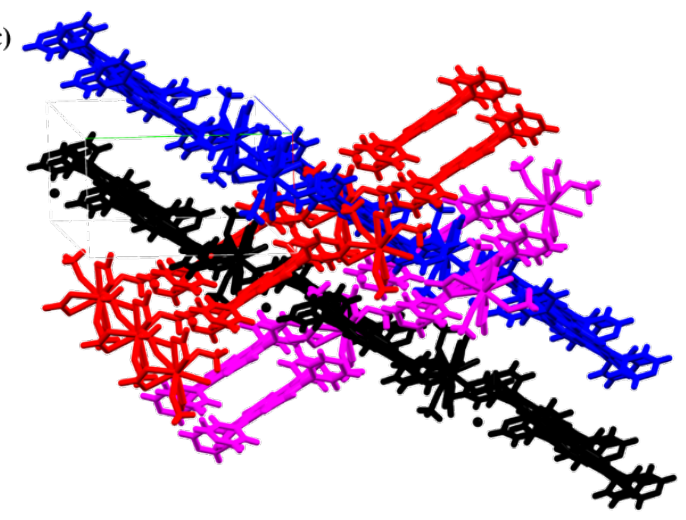

Figure 7. (a) 50\% Probability ellipsoid plot of 7. (b) Structure of an individual strong hydrogen bonded sheet. (c) Interpenetration of hydrogen bonded sheets to give 3D network (all atoms of a single color are part of the same hydrogen bonded sheet). (d) Packing diagram ( $2 \times 2 \times 2$ unit cells) viewed down $a$. 
The complex shows six separate short contacts which could potentially be strong hydrogen bonds between ligands coordinated to the $\mathrm{Ce}(\mathrm{III})$ center, the pyridine nitrogen atoms of the TPyP, and the non-coordinated water molecule. The donor-acceptor distances for these contacts range from 2.62(2) to 2.86(2) $\AA$. These hydrogen bonding interactions give rise to a complex three-dimensional network, which is further strengthened by a series of weaker $\mathrm{C}-\mathrm{H} \cdots \mathrm{O}$ interactions between both the methyl protons of the coordinated $\mathrm{MeOH}$, the aromatic protons of the TPyP, and the oxygen atoms of the $\left[\mathrm{NO}_{3}\right]$ anions, with $\mathrm{C}-\mathrm{H} \cdots \mathrm{O}$ donor-acceptor distances ranging from 3.19(2) to 3.49(2) $\AA$.

The network can be broken down by investigating the connectivity of the strongest hydrogen bonds, which are between TPyP, lattice $\mathrm{H}_{2} \mathrm{O}$ molecules, and $\mathrm{MeOH}$ ligands on $\mathrm{Ce}(\mathrm{III})$ complexes. These hydrogen bonds link the components of the crystal into infinite sheets (Figure 7b). These sheets are linked together through interpenetration to form a three dimensional network, as shown in Figure 7c, with interpenetrating sheets interacting only through weaker hydrogen bonds and dipole-dipole interactions. Each individual 2D sheet is symmetry equivalent, related by either a translation along $a$ or a 2 screw operation. As was the case in $\mathbf{1}$, due to the relative orientations of the two-dimensional sheets, adjacent TPyP molecules are approximately orthogonal to each other; although in contrast to 1, nearest parallel TPyP molecules are separated by the TCE solvent molecules packing between them (Figure 7d). This separation of adjacent TPyP molecules by solvent prevents any of the aromatic rings from coming close enough to form a $\pi$-stacking interaction, the shortest distance between centroids being $4.2 \AA$. The TCE solvent molecules, however, are held in place within the network by forming bridging $\mathrm{C}-\mathrm{H} \cdots \pi$ interactions with the TPyP molecules. These interactions allow the 
TCE molecules to bridge across the cavities they reside in, with the shortest $\mathrm{C}-\mathrm{H} \cdots \pi$ donor to acceptor distances being 3.45(3) and 3.37(3) Å, respectively.

Topological analysis also showed that the three-dimensional network is built up from linking of individual two-dimensional nets into a three-dimensional network through further hydrogen bonds. The individual two dimensional nets have the sql topology, ${ }^{101}$ with four-connected nodes based on both the Ce(III) complexes and the TPyP molecules. When considering the threedimensional net as a whole, it becomes apparent that the manner of linking of the sql nets together results in the three-dimensional net being self-penetrating, this being only the second reported self-penetrating network structure involving TPyP..$^{114}$

As a result of the interconnection of nets in the three-dimensional structure, the connectivity of the Ce-based nodes is increased to six, and their topology becomes more complex. The TPyPbased nodes retain the $4^{4} \cdot 6^{2}$ topology of the sql nets, while that of the Ce-based nodes becomes $4^{4} \cdot 6^{10} .8$, resulting in an overall network topology of $\left(4^{4} \cdot 6^{2}\right) \cdot\left(4^{4} \cdot 6^{10} \cdot 8\right)$. The resulting net has the topology of the face-centered cubic net, fsc; ${ }^{61}$ although, the net observed in $\mathbf{7}$ is structurally different to those seen previously, both in terms of its construction, and, particularly, its selfpenetration. One other TPyP compound, $\left\{\mathrm{Cu}(\mathrm{TPyP}) \mathrm{Cu}_{2} \mathrm{Mo}_{3} \mathrm{O}_{11}\right\}_{n}$, has been seen to exhibit the fsc net; however, it showed a more conventional form of the network. ${ }^{61}$

\section{Conclusions}

Following in Prof. Goldberg's footsteps, we have studied a large array of metal salt TPyP reactions. The seven new TPyP-containing species which were prepared and crystallographically characterized are diverse and interesting. Two were coordination polymers (1-2), four were complexes of porphyrinic salts (3-6), and one was a neutral molecular complex (7). While a 
previously known coordination mode was observed in $\mathbf{1}$, leading to a standard polymeric structure, more subtle effects led to an unusual packing motif for this type of polymeric structure. The structure of coordination polymer $\mathbf{2}$ showed was unique for its a previously unknown topology among TPyP structures, demonstrating only the second instance of TPyP behaving as a simple linker in a two-dimensional coordination polymer, and presenting a topologically uncommon three-dimensional through the linking of the coordination polymers by hydrogen bonding. The porphyrinic salts also showed features of interest. In the formation of the discrete hydrogen bonded dinuclear complex $\mathbf{5}$, the extension of this to a hydrogen-bonded network is seen to be blocked by abundance of hydrogen-bond acceptors in the system. In contrast the complexes 3,4 , and $\mathbf{6}$ all show the formation of hydrogen bonded networks, of topologies previously known for TPyP, but containing unusual features. The neutral molecular complex seen in $\mathbf{7}$ is also found to form an unusual hydrogen-bonded network, which shows a selfpenetrating variation on a previously known topology.

Despite the similarities in reaction conditions, a broad range of structural types emerged, and the spontaneous self-assembly of the specific components led to a variety of structural and topological features not seen previously in structures involving TPyP. Although these crystallizations were undertaken in non-aqueous systems that were at best only weakly acidic, $\mathrm{H}^{+}$ was able to out-compete metal ions for access to the pyridine groups of TPyP in most cases. The driving force for proton abstraction in these conditions appears to be the formation of salts with large counterions that form fairly dense noncovalent networks, often with solvent-filled micropores. The diversity of structures, which includes not only different nets but also different protonation states and coordination numbers, indicates that the systems likely have very complex solution speciation from which one especially stable structure is favored and can crystallize 
preferentially. Although this is a challenge for predicting the topology of TPyP based structures, it is extremely fruitful for allowing the discovery of unobserved topologies. Such studies could be particularly important in areas such as sensor development, where the spectroscopic response of particular supramolecular architectures provides a handle for discrimination. ${ }^{15}$

\section{ASSOCIATED CONTENT}

Crystallographic information is available in CIF format free of charge from the Cambridge Crystallographic Data Center (CCDC numbers 1905078-1905084).

\section{AUTHOR INFORMATION}

\section{Corresponding AuthorS}

SPK: kelleysp@missouri.edu

RDR: $\underline{\text { rdrogers@ua.edu }}$

\section{$\dagger$ Present Addresses}

MKM: Department of Pharmaceutics, College of Pharmacy, University of Minnesota, Minneapolis, MN 55455, U.S.A.

HC: Joint BioEnergy Institute, Sandia National Laboratory, Emeryville, CA 94608, U.S.A.

DBC: School of Chemistry, University of St. Andrews, St. Andrews, Scotland KY16 9ST, U.K.

\section{Author Contributions}


The manuscript was written through contributions of all authors. All authors have given approval to the final version of the manuscript.

\section{Funding Sources}

N/A

Notes

Any additional relevant notes should be placed here.

\section{ACKNOWLEDGMENT}

The authors would like to thank the University of Alabama Department of Chemistry and the University of Missouri-Columbia Department of Chemistry for support of this work.

\section{REFERENCES}

1. Desiraju, G. R. Supramolecular Synthons in Crystal Engineering - A New Organic Synthesis. Angew. Chem. Int. Ed. 1995, 34, 2311-2327.

2. Kumar, R. K.; Balasubramanian, S.; Goldberg, I. Supramolecular Multiporphyrin Architecture. Coordination Polymers and Open Networks in Crystals of Tetrakis(4cyanophenyl)- and Tetrakis(4-nitrophenyl)metalloporphyrin. Inorg. Chem. 1998, 37, 541552.

3. Sharma, C. V. K.; Broker, G. A.; Huddleston, J. G.; Baldwin, J. W.; Metzger, R. M.; Rogers, R. D. Design strategies for solid-state supramolecular arrays containing both mixed-metalated and freebase porphyrins. J. Am. Chem. Soc., 1999, 121, 1137-1144. 
4. Zhao, M.; Qu, S.; Wu, C. -D. Porous metal-organic frameworks for heterogeneous biomimetic catalysis. Acc. Chem. Res. 2014, 47, 1199-1207;

5. $\quad$ Xu, H. -Q.; Hu, J.; Wang, D.; Li, Z.; Zhang, Q.; Luo, Y.; Yu, S. -H.; Jiang, H. -L. Visible light photoreduction of $\mathrm{CO}_{2}$ in a metal-organic framework: Boosting electron-hole separation via electron trap states. J. Am. Chem. Soc. 2015, 137, 13440-13443.

6. Lee, C. Y.; Farha, O. K.; Hong, B. J.; Sarjeant, A. A.; Nguyen, S. B. T.; Hupp, J. T. Light-harvesting metal-organic frameworks (MOFs): Efficient strut-to-strut energy transfer in bodipy and porphyrin-based MOFs. J. Am. Chem. Soc. 2011, 133, 1585815861.

7. Seidel, R. W.; Goddard, R.; Föcker, K.; Oppel, I. M. Supramolecular Isomerism of SelfComplimentary Zinc-5,10,15,20-Tetra(4-pyridyl)porphyrin in the Presence of Dimethylformamide. CrystEngComm 2010, 12, 387-394.

8. Groom, C. R.; Bruno, I. J.; Lightfoot, M. P.; Ward, S. C. The Cambridge Structural Database. Acta Cryst. Sect. B. Struct. Sci. 2016, 72, 171-179.

9. Lipstman, S.; Goldberg, I. Coordination and hydrogen-bonding assemblies in hybrid reaction products between 5,10,15,20-tetra-4-pyridylporphyrin and dysprosium trinitrate hexahydrate. Acta Crystallogr. Sect. C: Cryst. Struct. Commun. 2010, 66, m222-m226.

10. Seidel, R. W.; I. M. Oppel, I. M. 1D and 2D solid-state metallosupramolecular arrays of freebase 5,10,15,20-tetra(4-pyridyl)porphyrin, peripherally linked by zinc and manganese ions. Struct. Chem., 2009, 20, 121-128. 
11. Ring, D. J.; Aragoni, M. C.; Champness, N. R.; Wilson, C. A coordination polymer supramolecular isomer formed from a single building block: An unexpected porphyrin ribbon constructed from zinc(tetra(4-pyridyl)porphyrin). CrystEngComm, 2005, 7, 621623.

12. Diskin-Posner, Y.; Patra, G. K.; Goldberg, I. Supramolecular assembly of metalloporphyrins in crystals by axial coordination through amine ligands. J. Chem. Soc. Dalton Trans, 2001, 2775-2782.

13. Sharma, C. V. K.; Broker, G. A.; Szulczewski, G. J.; Rogers, R. D. Self-assembly of freebase- and metalated-tetrapyridylporphyrins to modified gold surfaces. Chem. Commun., 2000, 1023-1024.

14. Sharma, C. V. K.; Broker, G. A.; Rogers, R. D. Polymorphous one-dimensional tetrapyridylporphyrin coordination polymers which structurally mimic aryl stacking interactions. J. Solid State Chem., 2000, 152, 253-260.

15. Kondo, M.; Kimura, Y.; Wada, K.; Mizutani, T.; Ito, Y.; Kitagawa, S. A new selfassembled porphyrin-silver(I) network. Chem. Lett. 2000, 818-819.

16. Pan, L.; Wang, X.; Noll, B. C. Self-assembly of free-base tetrapyridylporphyrin units by metal ion coordination. Chem. Commun. 1999, 157-158.

17. Zhang, N.; Guo, H.; Zhang, X. -Y.; Wang, W.; Wang, F. -Y.; Xiong, X. -X.; Wang, L.S. One simple method to synthesize copper(II) central-coordinated metalloporphyrin." Chin. J. Struct. Chem. 2017, 36, 1425-1432. 
18. Lipstman, S.; Goldberg, I. Coordination and hydrogen-bonding assemblies in hybrid reaction products between 5,10,15,20-tetra-4-pyridylporphyrin and dysprosium trinitrate hexahydrate. Acta Cryst. Sect. C. Cryst. Struct. Commun. 2010, 66, m222-m226.

19. Titi, H. M.; Patra, R; Goldberg, I. Exploring supramolecular self-assembly of tetraarylporphyrins by halogen bonding: Crystal engineering with diversely functionalized six-coordinate tin(L) ${ }_{2}$-porphyrin tectons. Chem. Eur. J. 2013, 19, 1494114949.

20. Han, Y.; Wu, Y.; Lai, W.; Cao, R. Electrocatalytic water oxidation by a water-soluble nickel porphyrin complex at neutral pH with low overpotential. Inorg. Chem. 2015, 54, $5604-5613$.

21. Smelser, A. M.; Li, Y. -F.; Carmichael, C. N.; Zhao, H. -Y.; Pan, W. -P.; Parkin, S.; Yan, B. Self-assembly of 1D metalloporphyrin array within pseudo hexagonal channels of polyoxometallates. Inorg. Chim. Acta 2011, 375, 122-127.

22. Zhang, W.; Jiang, P.; Wang, Y.; Zhang, J.; Zhang, P. Synthesis of two metal-porphyrin frameworks assembled from porphyrin building motifs, $5,10,15,20-$ tetrapyridylporphyrin and their base catalyzed property. Inorg. Chem. Commun. 2015, 61, 100-104.

23. Lourenço, L. M. O.; Fernandes, J. A.; Neves, M. G. P. M. S.; Cavaleiro, J. A. S.; Tomé, J. P. C.; Almeida Paz, F. A. 5,10,15,20-Tetrakis(1-methylpyrinium-4-yl)porphyrin tetraiodide tetrahydrate. Acta Cryst. Sect. E: Struct. Rep. 2011, 67, o3157-o3158. 
24. Zhu, X.-J.; Zhang, T.; Zhao, S.; Wong, W.-K.; Wong, W.-Y. Synthesis, structure, and photophysical properties of some gadolinium(III) porphyrinate complexes. Eur. J. Inorg. Chem. 2011, 3314-3320.

25. Zhang, J.; Gong, C.; Zeng, X.; Shu, J.; Xiao, P.; Xie, J. Fabrication of crystalline porphyinic polyoxometalate cluster with high thermal stability and exploration of its photocatalytic activity. Polyhedron 2017, 121, 95-100.

26. Zhu, X.-J.; Wang, P.; Leung, H. W. C.; Wong, W. -K.; Wong, W. -Y.; Kwong, D. W. J. Synthesis, characterization, and DNA-binding and -photocleavage properties of watersoluble lanthanide porphyrinate complexes. Chem. Eur. J. 2011, 17, 7041-7052.

27. Olijve, L .L. C.; How, E. N. W.; Bhadbhade, M.; Prasad, S.; Colbran, S. B.; Zhao, C.; Thordarson, P. Structural, electrochemical, and photochemical investigation of the atersoluble tin(IV) tetrakis(2- $N$-hydroxyethyl-4-pyridinium)porphyrin photocatalyst. $J$. Porphyr. Phthalocy. 2011, 15, 1345-1353.

28. Gao, F.; Zhu, G. -Z.; Yang, L.; Yao, M. -X. Cyanide-bridged heterobimetallic magnetic complexes based on metalloporphyrinate and tricyanometalate building blocks. New J. Chem. 2016, 40, 365-371.

29. Lipstman, S.; Goldberg, I. Porphyrin Framework Solids. Hybrid supramolecular assembly modes of tetrapyridylporphyrin and aqua nitrates of lanthanoid ions. Cryst. Growth Des., 2010, 10, 1823-1832. 
30. Koner, R.; Goldberg, I. Heteromolecular grids of free-base and zinc-tetra(4pyridyl)porphyrins with benzenetetracarboxylic acid. J. Inclusion Phenom. Macrocyclic Chem, 2010, 66, 403-408.

31. Seidel, R. W.; Oppel, I. M. Assembly of a rhomboidally distorted (4,4)-net based polymeric sheet structure bearing copper(II) 5,10,15,20-tetra(4-pyridyl)porphyrin. CrystEngComm 2010, 12, 1051-1053.

32. Seidel, R. W.; Oppel, I. M. 2D Metallosupramolecular arrays of zinc-5,10,15,20-tetra(4pyridyl)porphyrin via self-complementary coordination and peripheral linkage. Z. Anorg. Allg. Chem., 2010, 636, 446-448.

33. Lipstman, S.; Goldberg, I. New cyclic tetrameric and square-grid polymeric modes of supramolecular self-assembly of zinc tetra(4-pyridyl)porphyrin. CrystEngComm, 2010, $12,52-54$.

34. Koner, R.; Goldberg, I. Square-grid coordination networks of (5,10,15,20-tetra-4pyridylporphyrinato)zinc(II) in its clathrate with two guest molecules of 1,2dichlorobenzene: Supramolecular isomerism of the porphyrin self-assembly. Acta Crystallogr. Sect. C: Cryst. Struct. Commun., 2009, 65, m139-m142.

35. Lipstman, S.; Goldberg, I. Hydrogen-bonded three-dimensional network of a lanthanum(III) exocyclic complex with 5,10,15,20-tetra-4-pyridylporphyrin. Acta Crystallogr. Sect. C: Cryst. Struct. Commun., 2009, 65, m371-m373. 
36. Lipstman, S.; Goldberg, I. Versatile supramolecular reactivity of zinc-tetra(4pyridyl)porphyrin in crystalline solids: Polymeric grids with zinc dichloride and hydrogen-bonded networks with mellitic acid. Beilstein J. Org. Chem., 2009, 5, 77.

37. Koner, R.; Goldberg, I. Crystal engineering of molecular networks. Hydrogen bonding driven two-dimensional assmeblies of tetrapyridylporphyrin with benzene tri- and tetracarboxylic acids. CrystEngComm, 2009, 11, 1217-1219

38. Goldberg, I.; Muniappan, S.; George, S.; Lipstman, S. Self-assembly of uniquely structured porphyrin network solids by charged $\mathrm{N}-\mathrm{H} \cdots \mathrm{Cl}$ and $\mathrm{N}-\mathrm{H} \cdots \mathrm{O}$ hydrogen bonds. CrystEngComm, 2006, 8, 784-787.

39. Ohmura, T.; Usuki, A.; Fukumori, K.; Ohta, T.; Ito, M.; Tatsumi, K. New porphyrinbased metal-organic framework with high porosity: 2-D Infinite 22.2-Å square-grid coordination network. Inorg. Chem. 2006, 45, 7988-7990

40. Wang, J. -Q.; Ren, C. -X.; Weng, L. -H.; Jin, G. -X. Porphyrin-carborane organometallic assemblies based on 1,2-dicarbacloso-dodecaborane (12) ligands. Chem. Commun., 2006, 162-164.

41. Carlucci, L.; Ciani, G.; Proserpio, D. M.; Porta, F. Four new 2D porous polymeric frames from the self-assembly of silver triflate and silver tosylate with free-base and Znmetallated 5,10,15,20-tetra(4-pyridyl)porphyrin. CrystEngComm, 2005, 7, 78-86.

42. Jo, H. J.; Jung, S. H.; Kim, H. -J. Synthesis and hydrogen-bonded supramolecular assembly of trans-dihydroxotin(IV) tetrapyridylporphyrin complexes. Bull. Korean Chem. Soc., 2004, 25, 1869-1873. 
43. Pan, L.; Kelly, S.; Huang, X. Y.; Li, J. Unique 2D metalloporphyrin networks constructed from iron(II) and meso-tetra(4-pyridyl)porphyrin. Chem. Commun., 2002, 2334-2335.

44. Sun, D.; Tham, F. S.; Reed, C. A.; Boyd, P. D. W. Proc. Natl. Acad. Sci. 2002, 99, 50885092.

45. Kumar, R. K.; Goldberg, I. Supramolecular assembly of heterogeneous multiporphyrin arrays - structures of $\left[\left\{\mathrm{Zn}^{\mathrm{n}}(\mathrm{tpp})\right\}_{2}(\mathrm{tpyp})\right]$ and the coordination polymer $\left[\left\{\left[\mathrm{Mn}^{\mathrm{m}}(\mathrm{tpp})\right]_{2}(\mathrm{tpyp})\left(\mathrm{ClO}_{4}\right)_{2}\right\}_{\star}\right]$. Angew. Chem. Int. Ed. 1998, 37, 3027-3030.

46. Ohmura, T.; Setoyama, N.; Mukae, Y.; Usuki, A.; Senda, S.; Matsumoto, T.; Tatsumi, K. Supramolecular porphyrin-based metal organic frameworks: $\mathrm{Cu}$ (II) napthoate- $\mathrm{Cu}(\mathrm{II})$ tetrapyridyl porphine structures exhibiting selective $\mathrm{CO}_{2} / \mathrm{N}_{2}$ separation. CrystEngComm 2017, 19, 5173-5177.

47. Zou, C.; Zhang, Z.; Xu, X.; Gong, Q.; Li, J.; Wu, C. -D. A multifunctional organicinorganic hybrid structure based on $\mathrm{Mn}^{\mathrm{m}}$-porphyrin and polyoxometalate as a highly effective dye scavenger and heterogeneous catalyst. J. Am. Chem. Soc. 2012, 134, 87-90.

48. Xie, M.-H.; Yang, X. -L.; Zou, C.; Wu, C. -D. A Sn"v-porphyrin-based metal-organic framework for the selective photo-oxygenation of phenol and sulfides. Inorg. Chem. 2011, 50, 5318-5320.

49. Xiao, X.; Sun, J.; Jiang, J. X-ray structure of a Porphyrin-Tetramethylcucurbit[6]uril Supramolecular Polymer. Chem. Eur. J. 2013, 19, 16891-16896. 
50. Brancatelli, G.; De Zorzi, R.; Hickey, N.; Siega, P.; Zingone, G.; Geremia, S. New multicomponent porous architecture of self-assembled porphyrins/calixarenes driven by nickel ions. Cryst. Growth Des. 2012, 12, 5111-5117.

51. Sengupta, A.; Datta, S.; Su, C.; Herng, T. S.; Ding, J.; Vittal, J. J.; Loh, K. P. Tunable electrical conductivity and magnetic property of the two dimensional metal organic framework $\left[\mathrm{Cu}(\mathrm{TPyP}) \mathrm{Cu}_{2}\left(\mathrm{O}_{2} \mathrm{CCH}_{3}\right)_{4}\right]$. ACS Appl. Mater. Interfac. 2016, 8, 16154-16159.

52. DeVries, L.; Barron, P. M.; Hurley, E. P.; Chunhua, H.; Choe, W. "Nanoscale Lattice Fence" in a metal-organic framework: Interplay between hinged topology and highly anisotropic thermal response. J. Am. Chem. Soc. 2011, 133, 14848-14851.

53. Titi, H. M., Goldberg, I. Diamondoid framework solid with $\mathrm{Sn}\left(\mathrm{OCH}_{3}\right)_{2-}$ tetrapyridylporphyrin linkers, $\mathrm{Cu}$ nodes and $\left[\mathrm{Cu}^{\prime} \mathrm{Cl}_{2}\right]$ counter-ions. Acta Crystallogr. Sect. C. Struct. Chem. 2015, 71, 706-711.

54. George, S.; Goldberg, I. [5,10,15,20-Tetrakis(4-pyridyl)porphyrinato]zinc(II) acetic acid clathrate, and its unique polymeric honeycomb architecture. Acta Crystallogr. Sect. Sect. E: Struct. Rep. Online. 2005, 61, m1441-m1443

55. Hu, J. S.; Guo, Y. G.; Liang, H. P.; Wan, L. J.; Jiang, L. Three-dimensional selforganization of supramolecular self-assembled porphyrin hollow hexagonal nanoprisms. J. Am. Chem. Soc. 2005, 127, 17090-17095.

56. Lin, K. -J. SMTP-1: The first functionalized metalloporphyrin molecular sieves with large channels. Angew. Chem. Int. Ed. 1999, 38, 2730-2732. 
57. Krupitsky, H.; Stein, Z.; Goldberg, I.; Strouse, C. E. Crystalline complexes, coordination polymers and aggregation modes of tetra(4-pyridyl)porphyrin. J. Inclusion Phenom. Mol. Recognit. Chem. 1994, 18, 177-192.

58. Zheng, N.; Zhang, J.; Bu, X.; Feng, P. Cadmium-porphyrin coordination networks: Rich coordination modes and three-dimensional four-connected $\mathrm{CdSO}_{4}$ and $(3,5)$-connected hms nets. Cryst. Growth Des. 2007, 7, 2576-2581.

59. Abrahams, B. F.; Hoskins, B. F.; Robson, F. A new type of infinite 3D polymeric network containing 4-connected, peripherally-linked metalloporphyrin building blocks. $J$. Am. Chem. Soc. 1991, 113, 3606-3607.

60. Abrahams, B. F.; Hoskins, B. F.; Michail, D. M.; Robson, R. Assembly of porphyrin building blocks into network structures with large channels. Nature 1994, 369, 727-729.

61. Hagrman, D.; Hagrman, P. J.; Zubieta, J. Solid-state coordination chemistry: The selfassembly of microporous organic-inorganic hybrid frameworks constructed from tetrapyridylporphyrin and bimetallic oxide chains or oxide clusters. Angew. Chem. Int. Ed. 1999, 38, 3165-3168.

62. Jana, A. CSD Communication, 2017, 1566676.

63. Jana, A. CSD Communication, 2017, 1566677.

64. Dutta, G.; Jana A. K.; Natarajan S. Assembling porphyrins into extended network structures by employing aromatic dicarboxylates: Synthesis, metal exchange, and heterogeneous catalytic studies. Chem. Eur. J. 2017, 23, 8932-8940. 
65. Lipstman, S.; Goldberg, I. New cyclic tetrameric and square-grid polymeric modes of supramolecular self-assemply of zinc tetra(4-pyridyl)porphyrin. CrystEngComm 2010, $12,52-54$.

66. Titi, H. M.; Nandi, G.; Tripuramallu, B. K.; Goldberg, I. Exploring supramolecular selfassembly of tetraarylporphyrins by halogen interactions. 3. Tin( ()$_{2}\left(A_{2} B_{2}-\right.$ Porphyrin $)$ arrays supported by concerted halogen and hydrogen bonding. Cryst. Growth Des. 2015, $15,3063-3075$.

67. De Zorzi, R.; Guidolin, N.; Randaccio, L.; Geremia, S. A bifunctionalized porous material containing discrete assemblies of copper-porphyrins and calixarenes metallated by ion diffusion. CrystEngComm 2010, 12, 4056-4058.

68. Zhang, W.; Li, Y.; Sun, J. -H.; Tan, C. -P.; Ji, L. -N.; Mao, Z. W. Supramolecular selfassembled nanoparticles for chemo-photodynamic dual therapy against cisplatin resistant cancer cells. Chem. Commun. 2015, 51, 1807-1810.

69. Ohmura, T.; Usuki, A.; Mukae, Y.; Motegi, H.; Kajiya, S.; Yamamoto, M.; Senda, S.; Matsumoto, T.; Tatsumi, K. Supramolecular porphyrin-based metal-organic frameworks with fullerenes: Crystal structures and preferential intercalation of $\mathrm{C}_{r}$. Chem. Asian J. 2016, 11, 700-704.

70. Tsuchiya, Y.; Shiraki, T.; Matsumoto, T.; Sugikawa, K.; Sada, K., Yamano, A.; Shinkai, S. Supramolecular dye inclusion single crystals created from 2,3,6-trimethyl- $\beta$ cyclodextrin and porphyrins. Chem. Eur. J. 2012, 18, 456-465. 
71. Zhang, Z.; Zhang, L.; Wojtas, L.; Nugent, P.; Eddaoudi, M.; Zaworotko, M. J. Templated synthesis, postsynthetic metal exchange, and properties of a porphyrin-encapsulating metal organic framework. J. Am. Chem. Soc. 2012, 134, 924-927.

72. Zhang, Z.; Zhang, L.; Wojtas, L.; Eddaoudi, M.; Zaworotko, M. J. Template-directed synthesis of nets based on octahemioctahedral cages that encapsulate catalytically active metalloporphyrins. J. Am. Chem. Soc. 2012, 134, 928-933.

73. Larsen, R. W.; Miksova, J.; Mussleman, R.; Wojtas, L. Ground- and excited-state properties of $\mathrm{Zn}$ (II) tetrakis(4-tetramethylpyridyl) porphyrin specifically encapsulated within a Zn(II) HKUST metal-organic framework. J. Phys. Chem. A. 2011, 115, 1151911524.

74. Zhang, Z.; Gao, W. -Y.; Wojtas, L.; Ma, S.; Eddaoudi, M.; Zaworotko, M. J. Postsynthetic modification of porphyrin-encapsulating metal-organic materials by cooperative addition of inorganic salts to enhance $\mathrm{CO}_{2} / \mathrm{CH}_{4}$ selectivity. Angew. Chem. Int. Ed. 2012, $51,9330-9334$.

75. Zhang, Z.; Wojtas, L.; Eddaoudi, M.; Zaworotko, M. J. Stepwise transformation of the molecular building blocks in a porphyrin-encapsulating metal-organic material. J. Am. Chem. Soc. 2013, 135, 5982-5985.

76. Zhang, Z.; Wojtas, L.; Zaworotko, M. J. Three porphyrin-encapsulating metal-organic materials with ordered metalloporphyrin moieties. Cryst. Growth Des. 2014, 14, 15261530. 
77. Makowski, S. J.; Lacher, M.; Lermer, C.; Schnick, W. Supramolecular hydrogen-bonded structures between melamine and $N$-heterocycles. J. Mol. Struct. 2012, 1013, 19-25.

78. Xiao, X.; Li, W.; Jiang, J. Porphyrin-cucurbituril organic molecular porous material: Structure and iodine adsorption properties. Inorg. Chem. Commun. 2013, 35, 156-159.

79. Xu, J.; Xue, L. -J.; Hou, J. -L.; Yin, Z. -N.; Zhang, X.; Zhu, Q. -Y.; Dai, J. A strong donor-acceptor system based on a metal chalcogenide cluster and porphyrin. Inorg. Chem. 2017, 56, 8036-8044.

80. Adinehnia, M.; Borders, B.; Ruf, M.; Chilukuri, B.; Hipps, K. W.; Mazur, U. Comprehensive structure-function correlation of photoactive ionic $\pi$-conjugated supermolecular assemblies: An experimental and computational study. J. Mat. Chem. C 2016, 4, 10223-10229.

81. Yamada, Y.; Matsumoto, S.; Yamada, K.; Nishino, T.; Mihara, N.; Sugimoto, K.; Tanaka, K. Crystal structures of stacked ionic assemblies of tetracationic and tetraanionic porphyrins. Chem. Lett. 2014, 43, 1377-1379.

82. Tian, Y.; Beavers, C. M.; Busani, T.; Martin, K. E.; Jacobsen, J. L.; Mercado, B. Q.; Swartzentruber, B. S.; van Swol, F.; Medforth, C. J.; Shelnutt, J. A. Binary ionic porphyrin nanosheets: Electronic and light-harvesting properties regulated by crystal structure. Nanoscale 2012, 4, 1695-1700.

83. Xue, L. -J.; Huo, P.; Li, Y. -H.; Hou, J._L.; Zhu, Q. -Y.; Dai, J. An ionic chargetransfer dyad prepared cost-effectively from a tetrathiafulvalene carboxylate anion and a TMPyP cation. Phys. Chem. Chem. Phys. 2016, 18, 2940-2948. 
84. Li, K.; Titi, H. M.; Berton, P.; Rogers, R. D. Porphyrinic ionic liquid dyes: Synthesis and characterization. ChemistryOpen 2018, 7, 659-663.

85. Patra, R.; Titi, H. M.; Goldberg, I. Crystal engineering of molecular networks: Tailoring hydrogen bonding self assembly of tin-tetrapyridylporphyrins with multidentate carboxylic acids as axial ligands. Cryst. Growth Des. 2013, 13, 1342-1349.

86. Nandi, G.; Titi, H. M.; Goldberg, I. Exploring supramolecular self-assembly of metalloporphyrin tectons by halogen bonding. 2. Cryst. Growth Des. 2014, 14, 35573566.

87. Rani, J.; Raveendran, A.; Chaudhary, A.; Panda, M. K.; Patra, A. Polymorphism in Sn(IV)-tetrapyridyl porphyrins with a halogenated axial ligand: Structural, photophysical, and morphological study. Cryst. Growth Des. 2018, 18, 1437-1447.

88. SAINT, Area Detector Control and Integration Software Version 4, Siemens Analytical X-ray Systems, Inc.: Madison, WI, 1996.

89. Sheldrick, G. M. SADABS, Program for Semiempirical Absorption Correction of Area Detector Data, University of Göttingen: Germany, 1997.

90. Sheldrick, G. M. Crystal structure refinement with SHELXL. Acta Cryst. Sect. C. Struct. Chem. 2015, C71, 3-8.

91. Dolomanov, O. V.; Blake, A. J.; Champness, N. R.; Schroder, M. OLEX: New software for visualization and analysis of extended crystal structures. J. Appl. Crystallogr. 2003, $36,1283-1284$. 
92. Dolomanov, O. V.; Bourhis, L. J.; Gildea, R. J.; Howard, J. A. K.; Puschmann, H. OLEX2: A complete structure solution, refinement and analysis program. J. Appl. Cryst. 2009, 42, 339-341.

93. Macrae, C. F.; Bruno, I. J.; Chisholm, J. A.; Edgington, P. R.; McCabe, P.; Pidcock, E.; Rodgriquez-Monge, L.; Taylor, R.; van de Streek, J.; Wood, P. A. Mercury CSD 2.0 New features for the visualization and investigation of crystal structures. J. Appl. Cryst. 2008, 41, 466-470.

94. Spek, A. J. Appl. Crystallogr. 2003, 36, 7-13.

95. Bernardinelli, G.; Flack, H. D. Least-squares absolute structure refinement. Practical experience and ancillary calculations. Acta Crystallogr. Sect. A: Found. Crystallogr. 1985, $41,500-511$.

96. Flack, H. D. On enantiomorph-polarity estimation. Acta Crystallogr. Sect. A: Found. Crystallogr. 1983, 39, 876-881.

97. Thorn, A.; Dittritch, B.; Sheldrick, G. M. Enhanced rigid-bond restraints. Acta Cryst. Sect. A. Found. Adv. 2012, 68, 448-451.

98. Hunter, C. A.; Sanders, J. K. M. The nature of $\pi-\pi$ interactions. J. Am. Chem. Soc. 1990, $112,5525-5534$.

99. Wickleder, C.; Larsen, P. Crystal structure, second harmonic generation, and vibrational spectroscopy of $\mathrm{K}_{2} \mathrm{Mg}_{2}(\mathrm{SCN})_{6} \cdot 3 \mathrm{H}_{2} \mathrm{O}$. Chem. Mater. 2004, 16, 4016-4021. 
100. O’Keeffe, M.; Peskov, M. A.; Ramsden, S. J.; Yaghi, O. M. The reticular chemistry structure resource (RCSR) database of, and symbols for, crystal nets. Acc. Chem. Res. 2008, $41,1782-1789$.

101. Wells, A. F. Three-Dimensional Nets and Polyhedra, John Wiley \& Sons, New York, 1977.

102. Sposato, La Duca, R. L. Two- and three-dimensional aliphatic dicarboxylate copper coordination polymers with bis(3-pyridylmethyl)piperazine tethers. Polyhedron 2010, 29, 2239-2249.

103. Luo, F.; Che, Y. -X.; Zheng, J. -M. Highly rare ferromagnetic interaction with the $\mathrm{Cu}$ (tetrahedron)-Cu(square)-Cu(tetrahedron) mode observed in a 2-foled interpenetrating moganite net. Cryst. Growth Des., 2009, 9, 2047-2049.

104. Kostakis, G. E.; Malandrinos, G.; Nordlander, E.; Haukka, M.; Plakatouras, J. C. Solution and structural studies of the Cd(II) - aconitate system. Polyhedron 2009, 28, 3227-3234.

105. Zhang, L.; Li, Z. -J.; Qin, Y.-Y.; Zhang, J.; Cheng, J. -K.; Yin, P. -X.; Yao, Y. G. Homochiral moganite-type metal-organic framework based on unusual $\left(\mathrm{Ag}_{2} \mathrm{Cl}\right)_{n}$ skeletons. CrystEngComm 2008, 10, 655-657.

106. Hao, H. -Q.; Wang, J.; Liu, W. -T.; Tong, M. -L. Two 3D hybrid networks of mog and bcu topology constructed with copper (I/I,II) halides and $N$, $N$ '-spacers. CrystEngComm 2008, 10, 1454-1459. 
107. Hu, S.; Chen, J. -C., Tong, M. -L.; Wang, B.; Yan, Y. -X.; Batten, S. R. Cut-mediated dehydrogenative coupling and hydroxylation of an N-heterocyclic ligand: From generation of a new tetratopic ligand to the designed assembly of three-dimensional cpper(I) coordination polymers. Angew. Chem. Int. Ed. 2005, 44, 5471-5475.

108. Su, C. -Y.; Smith, M. D.; Goforth, A. M.; Zur Loye, H. -C. A three-dimensional, noninterpenetrating metal-organic framework with the moganite topology: A simple

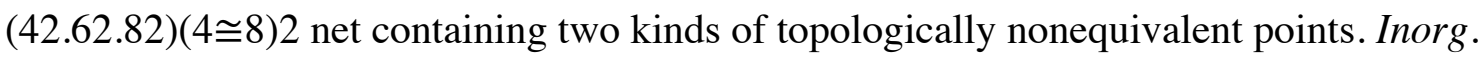
Chem. 2004, 43, 6881-6883.

109. Masciocchi, N.; Bruni, S.; Cariati, E.; Cariati, F.; galli, S.; Sironi, A. Extended polymorphism in copper(II) imidazolate polymers: A spectroscopic and XRPD structural study. Inorg. Chem. 2001, 40, 5897-5905.

110. Blatov, V. A. Multipurpose crystallochemical analysis with the program package TOPOS. IUCr CompComm Newsletter 2006, 7, 4-38.

111. Muniappan, S.; Lipstman, S.; George, S.; Goldberg, I. Porphyrin framework solids. Synthesis and structure of hybrid coordination polymers of tetra(carboxyphenyl)porphyrins and lanthanide-bridging ions. Inorg. Chem. 2007, 46, $5544-5554$.

112. Lipstman, S.; Goldberg, I. Unsolvated 5,10,15,20-tetra-4-pyridylporphyrin, its sesquihydrate and its 2-chlorophenol disolvate: Conformational versatility of the ligand. Acta Crystallogr. Sect. C: Cryst. Struct. Commun. 2009, 65, o447-o452. 
113. Greenwood, N.; Earnshaw, A. Chemistry of the Elements, Pergamon Press Ltd., Oxford, 1985.

114. Carlucci, L.; Ciani, G.; Proserpio, D. M.; orta, F. Open network architectures from the self-assembly of $\mathrm{AgNO}_{3}$ and 5,10,15,20-tetra(4-pyridyl)porphyrin ( $\mathrm{H}_{2}$ tpyp) building blocks: The exceptional self-penetrating topology of the 3D network of $\left[\mathrm{Ag}_{8}\left(\mathrm{Zn}^{\mathrm{t}} \mathrm{tpyp}\right)_{7}\left(\mathrm{H}_{2} \mathrm{O}\right)_{2}\right]\left(\mathrm{NO}_{3}\right)_{8}$. Angew. Chem. Int. Ed. 2003, 42, 317-322.

115. Lvova, L.; Natale, C. D.; Paolesse, R. Porphyrin-based chemical sensors and multi-sensor arrays operating in the liquid phase. Sensors and Actuators B: Chem. 2013, 179, 21-31. 


\section{For Table of Contents Use Only}

Structral Diversity in Tetrakis(4-pyridyl)porphyrin Supramolecular Building Blocks

Manish Kumar Mishra, Hemant Choudhary, David B. Cordes, Steven P. Kelley, Robin D.

Rogers

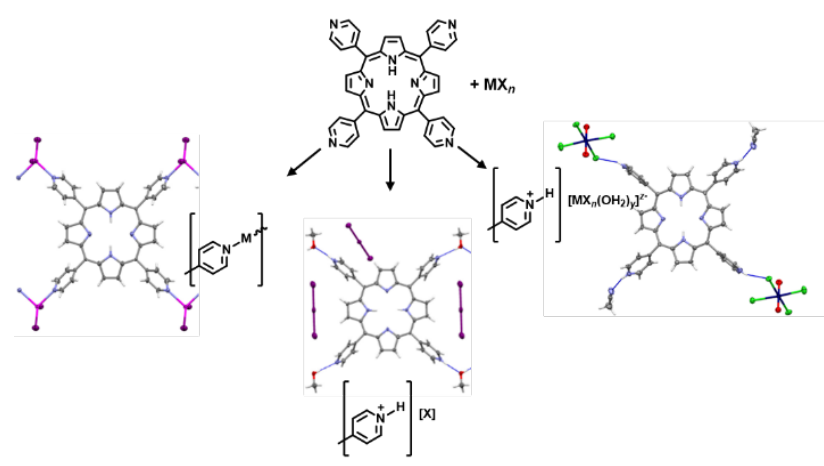

Synopsis: The supramolecular building block 5,10,15,20-tetra(4-pyridyl)porphyrin readily uses adventitious protons and metal complexes as well as direct coordination to assemble topologically variable supramolecular structures. 